\title{
Satellite observations of stratospheric hydrogen fluoride and comparisons with SLIMCAT calculations
}

\author{
Jeremy J. Harrison ${ }^{1,2}$, Martyn P. Chipperfield ${ }^{3,4}$, Christopher D. Boone ${ }^{5}$, Sandip S. Dhomse ${ }^{3,4}$, Peter F. Bernath ${ }^{6}$, \\ Lucien Froidevaux ${ }^{7}$, John Anderson ${ }^{8}$, and James Russell III ${ }^{8}$ \\ ${ }^{1}$ Department of Physics and Astronomy, University of Leicester, Leicester LE1 7RH, UK \\ ${ }^{2}$ National Centre for Earth Observation, University of Leicester, Leicester LE1 7RH, UK \\ ${ }^{3}$ Institute for Climate and Atmospheric Science, School of Earth and Environment, University of Leeds, Leeds LS2 9JT, UK \\ ${ }^{4}$ National Centre for Earth Observation, School of Earth and Environment, University of Leeds, Leeds LS2 9JT, UK \\ ${ }^{5}$ Department of Chemistry, University of Waterloo, Waterloo, Ontario N2L 3G1, Canada \\ ${ }^{6}$ Department of Chemistry and Biochemistry, Old Dominion University, Norfolk, Virginia 23529, USA \\ ${ }^{7}$ Jet Propulsion Laboratory, Pasadena, California 91109, USA \\ ${ }^{8}$ Department of Atmospheric and Planetary Sciences, Hampton University, Hampton, Virginia 23668, USA
}

Correspondence to: Jeremy J. Harrison (jh592@leicester.ac.uk)

Received: 22 October 2015 - Published in Atmos. Chem. Phys. Discuss.: 8 December 2015

Revised: 27 June 2016 - Accepted: 18 July 2016 - Published: 22 August 2016

\begin{abstract}
The vast majority of emissions of fluorinecontaining molecules are anthropogenic in nature, e.g. chlorofluorocarbons (CFCs), hydrochlorofluorocarbons (HCFCs), and hydrofluorocarbons (HFCs). Many of these fluorine-containing species deplete stratospheric ozone and are regulated by the Montreal Protocol. Once in the atmosphere they slowly degrade, ultimately leading to the formation of hydrogen fluoride (HF), the dominant reservoir of stratospheric fluorine due to its extreme stability. Monitoring the growth of stratospheric HF is therefore an important marker for the success of the Montreal Protocol.

We report the comparison of global distributions and trends of HF measured in the Earth's atmosphere by the satellite remote-sensing instruments ACE-FTS (Atmospheric Chemistry Experiment Fourier transform spectrometer), which has been recording atmospheric spectra since 2004, and HALOE (HALogen Occultation Experiment), which recorded atmospheric spectra between 1991 and 2005 , with the output of SLIMCAT, a state-of-the-art threedimensional chemical transport model. In general the agreement between observation and model is good, although the ACE-FTS measurements are biased high by $\sim 10 \%$ relative to HALOE. The observed global HF trends reveal a substantial slowing down in the rate of increase of HF since the 1990s: $4.97 \pm 0.12 \%$ year $^{-1}$ (1991-1997;
\end{abstract}

HALOE), $1.12 \pm 0.08 \%$ year $^{-1}$ (1998-2005; HALOE), and $0.52 \pm 0.03 \%$ year $^{-1}$ (2004-2012; ACE-FTS). In comparison, SLIMCAT calculates trends of 4.01, 1.10, and $0.48 \%$ year $^{-1}$, respectively, for the same periods; the agreement is very good for all but the earlier of the two HALOE periods. Furthermore, the observations reveal variations in the HF trends with latitude and altitude; for example, between 2004 and 2012 HF actually decreased in the Southern Hemisphere below $\sim 35 \mathrm{~km}$. An additional SLIMCAT simulation with repeating meteorology for the year 2000 produces much cleaner trends in $\mathrm{HF}$ with minimal variations with latitude and altitude. Therefore, the variations with latitude and altitude in the observed HF trends are due to variability in stratospheric dynamics on the timescale of a few years. Overall, the agreement between observation and model points towards the ongoing success of the Montreal Protocol and the usefulness of $\mathrm{HF}$ as a metric for stratospheric fluorine.

\section{Introduction}

The accumulation of fluorine in the Earth's atmosphere has resulted from anthropogenic emissions of organic molecules such as chlorofluorocarbons (CFCs), hydrochlorofluorocarbons (HCFCs), and hydrofluorocarbons (HFCs). The long 
atmospheric lifetimes of such molecules allow them to reach the stratosphere, where they break down and liberate fluorine in various inorganic forms. The most abundant of the emitted organic source molecules are CFC-12 $\left(\mathrm{CCl}_{2} \mathrm{~F}_{2}\right)$, CFC$11\left(\mathrm{CCl}_{3} \mathrm{~F}\right), \mathrm{CFC}-113\left(\mathrm{CCl}_{2} \mathrm{FCClF}_{2}\right)$, which are all now banned under the Montreal Protocol because they deplete stratospheric ozone, and $\mathrm{HCFC}-22\left(\mathrm{CHClF}_{2}\right)$, the most abundant HCFC and a transitional substitute under the Protocol. Although long-lived, these molecules do degrade in the atmosphere at high altitudes, ultimately to the long-lived stratospheric reservoir molecule hydrogen fluoride (HF); the chemistry schemes are presented below. Monitoring HF as part of the atmospheric fluorine family is important in closing the fluorine budget, particularly as anthropogenic emissions of fluorine species, many of which are ozone-depleting and all of which are greenhouse gases, have varied substantially over time. Certainly, monitoring the growth of stratospheric $\mathrm{HF}$, which has slowed in recent years, is an important marker for the success of the Montreal Protocol (in addition to monitoring stratospheric $\mathrm{HCl}$ ).

For the three most abundant fluorine source gases, CFC12, CFC-11, and HCFC-22, atmospheric degradation proceeds with the breaking of a $\mathrm{C}-\mathrm{Cl}$ (CFC-12 and $\mathrm{CFC}-11)$ or C-H (HCFC-22) bond (Ricaud and Lefevre, 2006):

$$
\begin{aligned}
& \mathrm{CCl}_{2} \mathrm{~F}_{2}+h v \rightarrow \mathrm{CClF}_{2}+\mathrm{Cl} \\
& \mathrm{CCl}_{3} \mathrm{~F}+h v \rightarrow \mathrm{CCl}_{2} \mathrm{~F}+\mathrm{Cl} \\
& \mathrm{CHClF}_{2}+\mathrm{OH} \rightarrow \mathrm{CClF}_{2}+\mathrm{H}_{2} \mathrm{O} .
\end{aligned}
$$

Depending on their structure, the intermediates produced in Reaction (R1) react further:

$$
\begin{aligned}
& \mathrm{CClF}_{2}+\mathrm{O}_{2}+M \rightarrow \mathrm{CClF}_{2} \mathrm{O}_{2}+M \\
& \mathrm{CClF}_{2} \mathrm{O}_{2}+\mathrm{NO} \rightarrow \mathrm{CClF}_{2} \mathrm{O}+\mathrm{NO}_{2} \\
& \mathrm{CClF}_{2} \mathrm{O}+\mathrm{O}_{2} \rightarrow \mathrm{COF}_{2}+\mathrm{ClO}_{2}, \\
& \mathrm{CCl}_{2} \mathrm{~F}+\mathrm{O}_{2}+M \rightarrow \mathrm{CCl}_{2} \mathrm{FO}_{2}+M \\
& \mathrm{CCl}_{2} \mathrm{FO}_{2}+\mathrm{NO} \rightarrow \mathrm{CCl}_{2} \mathrm{FO}+\mathrm{NO}_{2} \\
& \mathrm{CCl}_{2} \mathrm{FO}+\mathrm{O}_{2} \rightarrow \mathrm{COClF}+\mathrm{ClO}_{2} .
\end{aligned}
$$

For CFC-113, and minor sources such as HFCs (e.g. HFC134a, HFC-152a), the reaction scheme is similar.

In Reactions (R2) and (R3), carbonyl chloride fluoride $(\mathrm{COClF})$ and carbonyl fluoride $\left(\mathrm{COF}_{2}\right)$ are important "inorganic" reservoirs (the common terminology in atmospheric science differs from that in chemistry) of fluorine in the stratosphere, with lifetimes of 1.6 (Fu et al., 2009) and 3.8 (Harrison et al., 2014) years respectively; $\mathrm{COF}_{2}$ is more abundant than $\mathrm{COClF}$. The trends in these inorganic reservoirs over time are directly related to the trends of the individual source gases. The decrease in the amounts of atmospheric CFC-11 and CFC-113, the principal sources of carbonyl chloride fluoride, has led to a decreasing trend in this reservoir (Brown et al., 2011), whereas carbonyl fluoride is still slowly increasing over time due to the increase in
HCFC-22, which more than compensates for the decrease in the CFC-12 and CFC-113 source gases (Brown et al., 2011; Harrison et al., 2014).

$\mathrm{COClF}$ and $\mathrm{COF}_{2}$ volume mixing ratios (VMRs) slowly increase with altitude through the lower stratosphere until they reach their respective maxima, at $\sim 25-30 \mathrm{~km}$ for $\mathrm{CO}-$ $\mathrm{ClF}$ (Fu et al., 2009) and $\sim 30-40 \mathrm{~km}$ for $\mathrm{COF}_{2}$ (Harrison et al., 2014). Above these altitudes photolysis becomes more efficient, leading to the formation of fluorine atoms:

$$
\begin{aligned}
& \mathrm{COF}_{2}+h v \rightarrow \mathrm{FCO}+\mathrm{F} \\
& \mathrm{COClF}+h v \rightarrow \mathrm{FCO}+\mathrm{Cl} \\
& \mathrm{FCO}+\mathrm{O}_{2}+M \rightarrow \mathrm{FC}(\mathrm{O}) \mathrm{O}_{2}+M \\
& \mathrm{FC}(\mathrm{O}) \mathrm{O}_{2}+\mathrm{NO} \rightarrow \mathrm{FCO}_{2}+\mathrm{NO}_{2} \\
& \mathrm{FCO}_{2}+h v \rightarrow \mathrm{F}+\mathrm{CO}_{2} .
\end{aligned}
$$

The liberated fluorine atoms then react with methane, water, or molecular hydrogen to form the inorganic product HF. At the top of the stratosphere most of the fluorine is present as HF (Brown et al., 2014), the dominant reservoir of stratospheric fluorine due to its extreme stability. Note that due to this stability, $\mathrm{F}$ is not important for catalytic stratospheric ozone loss. HF is removed from the stratosphere by slow transport to, and rainout in, the troposphere or by upward transport to the mesosphere, where it is destroyed by photolysis (Duchatelet et al., 2010). Overall the amount of HF in the atmosphere is increasing (e.g. Brown et al., 2014).

The first detection of HF in the Earth's stratosphere, based on solar spectra recorded from balloon and on the ground at Jungfraujoch, was made by Zander et al. (1977). Measurements continue to be made at Jungfraujoch using a groundbased Fourier transform spectrometer (FTS) (e.g. Duchatelet et al., 2010). There have also been measurements of HF taken, for example, by the Atmospheric Trace MOlecule Spectrometry Experiment (ATMOS) instrument, which flew four times on NASA Space Shuttles between 1985 and 1994 (Irion et al., 2002), and the MkIV interferometer, a balloonborne solar occultation FTS (Velazco et al., 2011). Measurements taken by satellite-borne instruments, however, allow HF to be observed with global coverage and seasonal and latitudinal variability to be investigated fully. The first global atmospheric distributions of HF were provided by the HALogen Occultation Experiment (HALOE) instrument, onboard the Upper Atmosphere Research Satellite (UARS), which recorded atmospheric spectra between 1991 and 2005. More recently, the Atmospheric Chemistry Experiment FTS (ACEFTS), onboard the SCISAT satellite, has been recording atmospheric spectra since 2004, carrying the mantle of HF measurements into the second decade of the 21 st century. In fact, the ACE-FTS is the only satellite instrument currently taking measurements of HF.

This paper follows on from our recent work on the global distributions and trends of $\mathrm{COF}_{2}$, the most important "temporary" stratospheric fluorine reservoir that directly leads to 
the formation of HF. The aim of the present work is to understand the HF global distribution and trends derived from satellite observations taken by the HALOE and ACE-FTS instruments. To do this, we use the SLIMCAT model, a state-of-the-art three-dimensional (3-D) chemical transport model (CTM), one of the few to include stratospheric fluorine chemistry. Additionally, we compare tracer-tracer correlations between some of the major HF "sources" for SLIMCAT and satellite observations as a further test of the model chemistry.

\section{Hydrogen fluoride datasets}

\subsection{ACE-FTS}

The ACE-FTS instrument, which covers the spectral region 750 to $4400 \mathrm{~cm}^{-1}$ with a maximum optical path difference (MOPD) of $25 \mathrm{~cm}$ and a resolution of $0.02 \mathrm{~cm}^{-1}$ (using the definition of $0.5 / \mathrm{MOPD}$ throughout), uses the sun as a source of infrared (IR) radiation to record limb transmission through the Earth's atmosphere during sunrise and sunset ("solar occultation"). Transmittance spectra are obtained by ratioing against exo-atmospheric "high sun" spectra measured each orbit. These spectra, with high signalto-noise ratios, are recorded through long atmospheric limb paths ( $\sim 300 \mathrm{~km}$ effective length), thus providing a low detection threshold for trace species. ACE has an excellent vertical resolution of about $3-4 \mathrm{~km}$ and can measure up to 30 occultations per day, with each occultation sampling the atmosphere from $150 \mathrm{~km}$ down to the cloud tops (or $5 \mathrm{~km}$ in the absence of clouds). The locations of ACE occultations are dictated by the low Earth circular orbit of the SCISAT satellite and the relative position of the sun. Over the course of a year, the ACE-FTS records atmospheric spectra over a large portion of the globe (Bernath et al., 2005), from which it is possible to extract profiles of many fluorine-containing species, including $\mathrm{CCl}_{3} \mathrm{~F}$ (CFC11), $\mathrm{CCl}_{2} \mathrm{~F}_{2}$ (CFC-12), $\mathrm{CHClF}_{2}$ (HCFC-22), $\mathrm{CCl}_{2} \mathrm{FCClF}_{2}$ (CFC-113), $\mathrm{CH}_{3} \mathrm{CCl}_{2} \mathrm{~F}$ (HCFC-141b), $\mathrm{CH}_{3} \mathrm{CClF}_{2}$ (HCFC142b), $\mathrm{CH}_{2} \mathrm{FCF}_{3}$ (HFC-134a), $\mathrm{CHF}_{3}(\mathrm{HFC}-23), \mathrm{CF}_{4}, \mathrm{COF}_{2}$, COClF, $\mathrm{HF}$, and $\mathrm{SF}_{6}$.

The atmospheric pressure and temperature profiles, the tangent heights of the measurements, and the HF VMRs were taken from v3.0 (January 2004 until September 2010) and v3.5 (from October 2010) processing of the ACE-FTS data. Note that the retrieval scheme is identical for both the v3.0 and v3.5 datasets, the difference being in the meteorological data used as input for the pressure and temperature retrievals (the lowest ACE-FTS levels use these data directly). Due to an error in these inputs, v3.0 data should only be used for measurements taken until the end of September 2010, while v3.5 is valid for all ACE-FTS measurements. Details of the retrieval scheme for versions 3.0/3.5 processing have been explained elsewhere (e.g. Boone et al., 2013; Harrison
Table 1. Microwindows for the v3.0/v3.5 ACE-FTS hydrogen fluoride retrieval.

\begin{tabular}{rrrr}
\hline $\begin{array}{r}\text { Centre } \\
\text { frequency } \\
\left(\mathrm{cm}^{-1}\right)\end{array}$ & $\begin{array}{r}\text { Microwindow } \\
\text { width } \\
\left(\mathrm{cm}^{-1}\right)\end{array}$ & $\begin{array}{r}\text { Lower } \\
\text { altitude } \\
(\mathrm{km})\end{array}$ & $\begin{array}{r}\text { Upper } \\
\text { altitude } \\
(\mathrm{km})\end{array}$ \\
\hline 3787.60 & 1.60 & 40 & $2.00 \times 10^{16 \mathrm{~b}}$ \\
3788.28 & 0.60 & 12 & 40 \\
$3792.65^{\mathrm{a}}$ & 0.40 & 20 & 40 \\
3833.70 & 0.80 & 16 & 40 \\
3834.30 & 1.60 & 40 & $9.00 \times 10^{15 \mathrm{~b}}$ \\
3877.60 & 0.80 & 12 & $9.00 \times 10^{15 \mathrm{~b}}$ \\
3920.15 & 0.70 & 25 & $9.00 \times 10^{15 \mathrm{~b}}$ \\
4000.87 & 0.65 & 12 & $9.00 \times 10^{15 \mathrm{~b}}$ \\
4038.82 & 1.00 & 12 & $9.00 \times 10^{15 \mathrm{~b}}$ \\
4075.35 & 0.80 & 25 & $9.00 \times 10^{15 \mathrm{~b}}$ \\
4109.75 & 0.80 & 25 & $2.00 \times 10^{16 \mathrm{~b}}$ \\
\hline a Included to improve results for interferer HDO. ${ }^{\mathrm{b}}$ Upper altitude given \\
in atmospheric density units, molecules cm ${ }^{-3}$.
\end{tabular}

et al., 2014). Briefly, vertical profiles of trace gases (along with temperature and pressure) are derived from the recorded transmittance spectra via an iterative Levenberg-Marquardt nonlinear least-squares global fit to the selected spectral region(s) for all measurements within the altitude range of interest. The microwindow set and associated altitude ranges for the HF retrieval are listed in Table 1. The VMRs for molecules with absorption features in the microwindow set (see Table 2) were adjusted simultaneously with the HF amount. All spectroscopic line parameters were taken from the HITRAN 2004 database (Rothman et al., 2005), with HF parameters apparently unchanged since HITRAN 1992. The microwindow set covers eight spectroscopic lines $\left(\mathrm{P}_{1}, \mathrm{P}_{2}\right.$, $\mathrm{P}_{3}, \mathrm{P}_{4}, \mathrm{R}_{0}, \mathrm{R}_{1}, \mathrm{R}_{2}, \mathrm{R}_{3}$ ) from the fundamental (1-0) band of HF. The HF retrieval extends from a lower altitude of $12 \mathrm{~km}$ up to altitudes corresponding to an atmospheric density of $9.0 \times 10^{15}$ molecules $\mathrm{cm}^{-3}$, in practice $\sim 50-55 \mathrm{~km}$, thus providing a variation in upper altitude with both latitude and season (see Table 1). The HF spectral signal in ACEFTS spectra recorded above the upper altitude retrieval limit is generally below the noise level, so it is not possible to retrieve VMRs directly at these altitudes. Instead, the VMR profile above the highest analysed ACE measurement is calculated by scaling the "initial" VMR profile, taken from ATMOS measurements (Irion et al., 2002), over these altitudes; the scaling factor is determined during the least-squares fitting.

\subsection{HALOE}

Like the ACE-FTS, the HALOE instrument (Russell III et al., 1993) used the principle of solar occultation to sound the middle atmosphere at sunset and sunrise (relative to the instrument). HALOE used broadband and gas-filter radiome- 
try, with channels covering selected portions of the spectrum between 2.45 and $10.04 \mu \mathrm{m}$, to determine the mixing ratios of molecules related to the chemistry of stratospheric ozone and its destruction by CFCs. In particular, HALOE provided measurements of $\mathrm{O}_{3}, \mathrm{HCl}, \mathrm{HF}, \mathrm{CH}_{4}, \mathrm{H}_{2} \mathrm{O}, \mathrm{NO}, \mathrm{NO}_{2}$, aerosol extinction, and temperature vs. pressure, over an altitude range of $\sim 15$ to $60-130 \mathrm{~km}$ depending on channel (HF, $\mathrm{HCl}$, $\mathrm{CH}_{4}$, and $\mathrm{NO}$ were measured using gas filter radiometry). As with the ACE-FTS, the locations of HALOE occultations and hence the extent of its global coverage were dictated by its orbit and the relative position of the sun. HALOE, with an orbit inclination of $57^{\circ}$ compared with $74^{\circ}$ for the ACE-FTS, had a more even latitudinal coverage and provided more data over tropical regions, for example, than the ACE-FTS, which takes most of its measurements at high latitude.

The atmospheric pressure, temperature, tangent heights, and HF VMRs were taken from version 19 processing of the HALOE data, which are available from October 1991 to November 2005. The retrieval scheme incorporates a simple "onion peeling" approach stabilised at the top and bottom of the profile with a scalar optimal estimation formulation developed by Connor and Rodgers (1989). For the HF channel, the spectral bandpass $5 \%$ relative response points are 4025 and $4135 \mathrm{~cm}^{-1}$. The HF spectral line parameters were taken from the HITRAN 1992 database (Rothman et al., 1992). The instantaneous vertical field of view in the limb is $\sim 1.6 \mathrm{~km}$. Detailed validation studies for HALOE HF measurements were published by Russell III et al. (1996). Note that for internal consistency with previous work on the fluorine budget (Brown et al., 2014) and $\mathrm{COF}_{2}$ (Harrison et al., 2014), the vertical pressure grid has been interpolated onto the standard $1 \mathrm{~km}$ grid used by the ACE-FTS.

\subsection{GOZCARDS}

The ACE-FTS, HALOE, and SLIMCAT model time series are also compared with those of the GOZCARDS (Global OZone Chemistry And Related Datasets for the Stratosphere) HF data product in Sect. 5. GOZCARDS provides a global long-term stratospheric Earth System Data Record (ESDR) for stratospheric ozone and related chemical species, including HF. The HF data record was not ready in time to be included in the original dataset provided for public usage (temperature, $\mathrm{O}_{3}, \mathrm{H}_{2} \mathrm{O}, \mathrm{HCl}, \mathrm{N}_{2} \mathrm{O}$, and $\mathrm{HNO}_{3}$ ); we are presenting the $\mathrm{HF}$ data for the first time here. Froidevaux et al. (2015) have described the GOZCARDS data creation methodology and some stratospheric characteristics concerning the latter five species. The constituent datasets are time series of monthly zonal means vs. latitude (in $10^{\circ}$ latitude bins) taken from existing satellite datasets. In particular, the GOZCARDS HF data product is derived by merging the v19 HALOE (1991-2005) and v2.2 ACE-FTS (2004-2010) datasets, with the relative bias between source datasets removed by averaging them over the overlap period 2004-2005 and adjusting the series accordingly; note that such a process
Table 2. Interferers in the v3.0/v3.5 ACE-FTS hydrogen fluoride retrieval.

\begin{tabular}{lrr}
\hline Molecule & $\begin{array}{r}\text { Lower altitude } \\
\text { limit }(\mathrm{km})\end{array}$ & $\begin{array}{r}\text { Upper altitude } \\
\text { limit }(\mathrm{km})\end{array}$ \\
\hline $\mathrm{H}_{2} \mathrm{O}$ & 12 & 65 \\
$\mathrm{H}^{18} \mathrm{OH}$ & 12 & 50 \\
$\mathrm{H}^{17} \mathrm{OH}$ & 12 & 40 \\
$\mathrm{HDO}$ & 12 & 25 \\
$\mathrm{CO}_{2}$ & 12 & 40 \\
$\mathrm{O}_{3}$ & 12 & 38 \\
$\mathrm{CH}_{4}$ & 12 & 30 \\
$\mathrm{OC}^{18} \mathrm{O}$ & 12 & 20 \\
$\mathrm{~N}_{2} \mathrm{O}$ & 12 & 30 \\
\hline
\end{tabular}

does not account for any systematic biases in the original datasets. All GOZCARDS datasets are provided on a vertical pressure grid. Again, to be consistent with previous ACE work, this vertical pressure grid has been interpolated onto the standard $1 \mathrm{~km}$ grid used by the ACE-FTS. Note that as this GOZCARDS dataset uses v2.2 ACE-FTS data, the time series terminates in September 2010.

\section{Retrieval errors}

\subsection{Infrared spectroscopy of hydrogen fluoride}

One of the major sources of systematic error for any retrieved atmospheric profile arises from uncertainties in the laboratory spectroscopic data. A discussion of spectroscopic errors is therefore appropriate. The ACE-FTS retrieval makes use of HF line parameters first made available as part of the HITRAN 1992 database (and remaining unchanged until the HITRAN 2012 release), with partition data taken from the Total Internal Partition Sums (TIPS) subroutine included in the HITRAN compilation. HITRAN simply provides error codes for line parameters in the form of uncertainty ranges but with no information as to how the parameters are correlated. For the HF line parameters used in this work, the errors correspond to $0.0001-0.001 \mathrm{~cm}^{-1}$ for the line wavenumber, $v, 2-5 \%$ for the line intensity, $S$, and $1-2 \%$ for the air-broadened half-width, $\gamma_{\text {air }}$. Errors are unreported for $\gamma_{\text {self }}$ (self-broadened half-width), $n_{\text {air }}$ (temperature-dependent exponent for $\gamma_{\text {air }}$ ), and $\delta_{\text {air }}$ (air-pressure-induced line shift). Recently, and after v3.0 processing of the ACE data was complete, HITRAN 2012 became available; it includes a complete re-evaluation of HF spectroscopy. The associated publication (Rothman et al., 2013) also explains that all the airbroadening parameters, $\gamma_{\text {air }}$, for the fundamental band of $\mathrm{HF}$ were fitted with the Galatry profile, not the Voigt profile, which is the lineshape of choice for the HITRAN database. Additionally, the Dicke narrowing parameters in the original analysis were simply neglected. For the purposes of this 
work, we assume a retrieval error of at most $\sim 4 \%$, arising from uncertainties in HF line parameters.

\subsection{ACE-FTS}

The ACE v2.2 HF data product, which uses a slightly different microwindow set from v3.0/v3.5 as well as an earlier version of the PT retrieval, has previously been validated, for example, against measurements taken by HALOE and the MkIV interferometer (Mahieu et al., 2008). It was found that ACE-FTS v2.2 HF measurements are biased high compared to HALOE, with mean differences around 5-20\% between 15 and $49 \mathrm{~km}$. Comparison of ACE-FTS v2.2 HF with MkIV data is generally good, with relative differences above $19 \mathrm{~km}$ within $\pm 10 \%$. There have been no detailed comparisons in the literature between ACE-FTS v2.2 and v3.0 HF datasets, although Duchatelet et al. (2010) suggest that ACE-FTS v3.0 HF VMRs have decreased by close to $5 \%$ relative to v2.2. However, a re-evaluation of filtered v2.2 and v3.0/v3.5 HF data carried out as part of this work indicates good agreement within $\pm 5 \%$, with no significant overall bias between the two datasets.

The $1 \sigma$ statistical fitting errors for a single ACE profile are typically $\sim 5 \%$ over most of the altitude range. These errors are random in nature and largely determined by the measurement noise of the ACE-FTS. Averaged profiles tend to be dominated by systematic errors, with random errors reduced by a factor of $1 / \sqrt{ } N$, where $N$ is the number of profiles averaged. Spectroscopic sources of systematic error predominantly arise from the HF HITRAN line list ( $\sim \%$; see Sect. 3.1), with minor contributions from interfering species that absorb in the microwindow regions; we assume that these contributions are small, at most $1 \%$, due to the lack of systematic features in the spectral residuals (Harrison et al., 2014). Additional systematic errors arise from uncertainties in temperature, pressure, tangent altitude (i.e. pointing), and instrumental line shape (ILS); these were estimated by running the ACE-FTS retrieval for a subset of occultations, with each quantity $\left(b_{j}\right)$ perturbed in turn by its assumed $1 \sigma$ uncertainty $\left(\Delta b_{j}\right)$. The fractional retrieval error, $\mu_{j}$, is defined as

$\mu_{j}=\left|\frac{\operatorname{VMR}\left(b_{j}+\Delta b_{j}\right)-\operatorname{VMR}\left(b_{j}\right)}{\operatorname{VMR}\left(b_{j}\right)}\right|$.

Note that pressure, temperature, and tangent height are not strictly independent quantities for ACE-FTS retrievals; tangent heights are determined from hydrostatic equilibrium, and so these quantities are strongly correlated. Therefore, only two of these three quantities are altered: temperature is adjusted by $2 \mathrm{~K}$ and tangent height by $150 \mathrm{~m}$ (Harrison et al., 2014). ILS uncertainty is determined by adjusting the field of view by $5 \%$ (Harrison et al., 2014). A subset of 81 occultations measured between 65 and $70^{\circ} \mathrm{N}$ in July 2010 was selected for this analysis. The fractional value estimates of the systematic uncertainties, and their symbols, are given in
Table 3. Sources of systematic uncertainty in the ACE-FTS v3.0/v3.5 hydrogen fluoride retrieval.

\begin{tabular}{llr}
\hline Source & Symbol & Fractional value \\
\hline HF spectroscopy & $\mu_{\mathrm{spec}}$ & 0.04 \\
Spectral interferers & $\mu_{\text {int }}$ & 0.01 \\
Temperature & $\mu_{T}$ & 0.01 \\
Altitude & $\mu_{z}$ & 0.03 \\
ILS & $\mu_{\text {ILS }}$ & 0.09 \\
\hline
\end{tabular}

Table 3. Assuming uncorrelated quantities, the overall systematic error in the HF retrieval can be calculated as

$\mu_{\text {systematic }}^{2}=\mu_{\mathrm{spec}}^{2}+\mu_{\mathrm{int}}^{2}+\mu_{T}^{2}+\mu_{z}^{2}+\mu_{\mathrm{ILS}}^{2}$.

The total systematic error contribution to the ACE-FTS HF retrieval is estimated to be $\sim 10 \%$ over the altitude range of the retrieval.

As discussed in Sect. 3.1, HF VMRs are not directly retrieved for ACE measurements taken at tangent heights above the upper altitude limits listed in Table 1. In the ACE-FTS $\mathrm{HF}$ retrieval, the calculated spectrum is generated from the sum of contributions from the tangent layer up to $150 \mathrm{~km}$. For the highest analysed measurement, the retrieved VMR in the tangent layer is generated from the piecewise quadratic interpolation scheme (Boone et al., 2013), while the VMR in every layer above that is determined from scaling the "initial" VMR profile, with the scaling factor determined during the retrieval by forcing the calculated spectrum to match as best as possible the measured spectrum for the highest analysed measurement. Since the "initial" profile is fixed to a constant VMR between 50 and $100 \mathrm{~km}$ altitude, and since this portion of the profile is scaled based on the VMR of the highest analysed ACE measurement, this will likely introduce systematic errors into the highest altitudes of the retrieved profile. However, since the scaling factor errors are dominated by the $1 \sigma$ statistical fitting errors of the highest analysed ACE measurement, it is anticipated that the systematic errors at the top of the profiles are reduced when they are averaged to create zonal means.

\subsection{HALOE}

As discussed in Sect. 3.2, HALOE v19 HF has been validated against ACE-FTS v2.2, with the ACE measurements biased high by around 5-20\% between 15 and $49 \mathrm{~km}$ (Mahieu et al., 2008). Furthermore, HF data from the MkIV interferometer for three flights (2003-2005) agree well with ACE-FTS, with relative differences above $19 \mathrm{~km}$ within $\pm 10 \%$, suggesting that there is a low bias in HALOE. Detailed HALOE HF error estimates and validation studies have previously been conducted by Russell III et al. (1996). The estimated errors range from $\sim 27 \%$ at $100 \mathrm{hPa}$ to $15 \%$ at $1 \mathrm{hPa}$. Actual mean differences between HALOE and balloon data from a series of nine FTS under-flights, five operating in the far-IR and 
four MkIV comparisons in the near-IR, collectively ranged from more than $17 \%$ below $70 \mathrm{hPa}$, where the mixing ratio is very low to $<7 \%$ above that level, with no positive or negative bias implied. These HALOE data were produced using an early algorithm version, but results have proven to be very stable for later versions.

\section{TOMCAT/SLIMCAT 3-D chemical transport model}

SLIMCAT, an offline 3-D CTM, calculates the abundances of a number of stratospheric trace gases from prescribed sourcegas surface boundary conditions and a detailed treatment of stratospheric chemistry, including the major species in the $\mathrm{O}_{x}, \mathrm{NO}_{y}, \mathrm{HO}_{x}, \mathrm{~F}_{y}, \mathrm{Cl}_{y}$, and $\mathrm{Br}_{y}$ chemical families (e.g. Chipperfield, 1999; Feng et al., 2007). The model uses winds from meteorological analyses to specify winds and temperatures. This approach gives a realistic stratospheric circulation (Chipperfield, 2006; Monge-Sanz et al., 2007). In the version used here the troposphere is assumed to be well mixed.

For this study SLIMCAT was integrated from 1977 to 2013 at a horizontal resolution of $5.6^{\circ} \times 5.6^{\circ}$ and 32 levels from the surface to $60 \mathrm{~km}$. The model uses a $\sigma-p$ vertical coordinate (Chipperfield, 2006) and was forced by European Centre for Medium-Range Weather Forecasts (ECMWF) reanalyses (ERA-Interim from 1979 onwards). The VMRs of source gases at the surface level were specified using datasets prepared for the WMO/UNEP (2011) ozone assessment. These global mean surface values define the long-term tropospheric source-gas trends in the model. Similarly, specification of the surface VMRs of degradation products acts as a sink for these species. The model initialisation used the estimated halocarbon loading for 1977, taken from the WMO/UNEP scenarios.

The SLIMCAT run makes use of the same chemistry scheme that was previously used for our work on $\mathrm{COF}_{2}$ (Harrison et al., 2014); however, in the present version the photolysis scheme has been updated to use latitudinally and monthly varying ozone profile shapes in the photolysis lookup table. All source and degradation products related to fluorine chemistry are listed in Table $4 . \mathrm{COF}_{2}$ contributions arise from the degradation of CFC-12, CFC-113, CFC114, CFC-115, HCFC-22, HCFC-142b, HFC-23, HFC-134a, HFC-152a, Halon 1211, and Halon 1301, with COClF production arising from the degradation of CFC-11, CFC-113, and $\mathrm{HCFC}-141 \mathrm{~b}\left(\mathrm{CH}_{3} \mathrm{CCl}_{2} \mathrm{~F}\right)$. Some $\mathrm{HF}$ is assumed to form directly from the source gases (see Table 4), but this is almost negligible in practical terms $(\sim 3 \%$ in 2010 , mainly arising from $\mathrm{HFC}-134 \mathrm{a}$ ). The relative amounts of $\mathrm{HF}$ formed (in 2010) via $\mathrm{COClF}$ and $\mathrm{COF}_{2}$ are 30 and $67 \%$ respectively.

The SLIMCAT calculations reveal that at altitudes above the maximum $\mathrm{COClF}$ and $\mathrm{COF}_{2} \mathrm{VMRs}$, there is net loss of these at all latitudes. The primary loss of $\mathrm{COF}_{2}$ and $\mathrm{COClF}$ in the stratosphere occurs via photolysis, with an additional secondary loss mechanism through reaction with $\mathrm{O}\left({ }^{1} \mathrm{D}\right)$; SLIM-
Table 4. Fluorine source gases in the SLIMCAT chemical scheme and their atmospheric degradation products.

\begin{tabular}{|c|c|c|}
\hline \multicolumn{2}{|c|}{ Source gases } & \multirow[t]{2}{*}{ Product gases } \\
\hline Commercial name & Chemical formula & \\
\hline CFC-11 & $\mathrm{CCl}_{3} \mathrm{~F}$ & $\mathrm{COClF}$ \\
\hline CFC-12 & $\mathrm{CCl}_{2} \mathrm{~F}_{2}$ & $\mathrm{COF}_{2}$ \\
\hline CFC-113 & $\mathrm{CCl}_{2} \mathrm{FCClF}_{2}$ & $\mathrm{COClF}+\mathrm{COF}_{2}$ \\
\hline CFC-114 & $\mathrm{CClF}_{2} \mathrm{CClF}_{2}$ & $2 \mathrm{COF}_{2}$ \\
\hline CFC-115 & $\mathrm{CClF}_{2} \mathrm{CF}_{3}$ & $2 \mathrm{COF}_{2}+\mathrm{HF}$ \\
\hline HCFC-22 & $\mathrm{CHClF} 2$ & $\mathrm{COF}_{2}$ \\
\hline HCFC-141b & $\mathrm{CH}_{3} \mathrm{CCl}_{2} \mathrm{~F}$ & $\mathrm{COClF}$ \\
\hline HCFC-142b & $\mathrm{CH}_{3} \mathrm{CClF}_{2}$ & $\mathrm{COF}_{2}$ \\
\hline HFC-23 & $\mathrm{CHF}_{3}$ & $\mathrm{COF}_{2}+\mathrm{HF}$ \\
\hline HFC-134a & $\mathrm{CH}_{2} \mathrm{FCF}_{3}$ & $\mathrm{COF}_{2}+2 \mathrm{HF}$ \\
\hline HFC-152a & $\mathrm{CH}_{3} \mathrm{CHF}_{2}$ & $2 \mathrm{COF}_{2}$ \\
\hline Halon 1211 & $\mathrm{CBrClF}_{2}$ & $\mathrm{COF}_{2}$ \\
\hline Halon 1301 & $\mathrm{CBrF}_{3}$ & $\mathrm{COF}_{2}+\mathrm{HF}$ \\
\hline \multirow[t]{3}{*}{ Halon 2402} & $\mathrm{CBrF}_{2} \mathrm{CBrF}_{2}$ & $4 \mathrm{HF}$ \\
\hline & $\mathrm{IF}^{*}$ & $\mathrm{HF}$ \\
\hline & & $2 \mathrm{HF}$ \\
\hline
\end{tabular}

* These are not source gases, but their degradation products are included for completion.

CAT calculates relative contributions of, respectively, 90 and $10 \%$ for $\mathrm{COF}_{2}$ (Harrison et al., 2014) and 98 and $2 \%$ for COCIF. The SLIMCAT outputs enable an estimation of the atmospheric lifetimes of $\mathrm{COF}_{2}$ and $\mathrm{COClF}$ by dividing the total modelled atmospheric burden of each species by the total calculated atmospheric loss rate. The total calculated mean atmospheric lifetimes are 3.9 years for $\mathrm{COF}_{2}$, revised upwards from the calculated value of 3.8 years presented by Harrison et al. (2014), and 1.7 years for COClF.

\section{Comparison between ACE-FTS/HALOE/SLIMCAT datasets}

The ACE-FTS HF data were binned into five latitude bands by month; VMRs outside six median absolute deviations (MAD) of the median VMR for each bin and altitude were removed from the analysis. Once filtered to remove significant outliers, the data were used to create monthly zonal means at each altitude within $5^{\circ}$ latitude bins. In Fig. 1 these have been plotted next to SLIMCAT zonal means for the months September 2009 to August 2010, thereby revealing the seasonal variation in the HF distribution over this period. Note that these dates have been chosen to match those used in the previous work on carbonyl fluoride (see Fig. 11 of Harrison et al., 2014). The HF profiles generally show an increase in VMR with altitude, with the rate of this increase varying with latitude and time of year. Note that ACE-FTS observations do not cover all latitude bins over a single month (see Sect. 2.1) and that latitude bins containing fewer occultations are noisier in appearance. Despite these caveats, Fig. 1 reveals a 


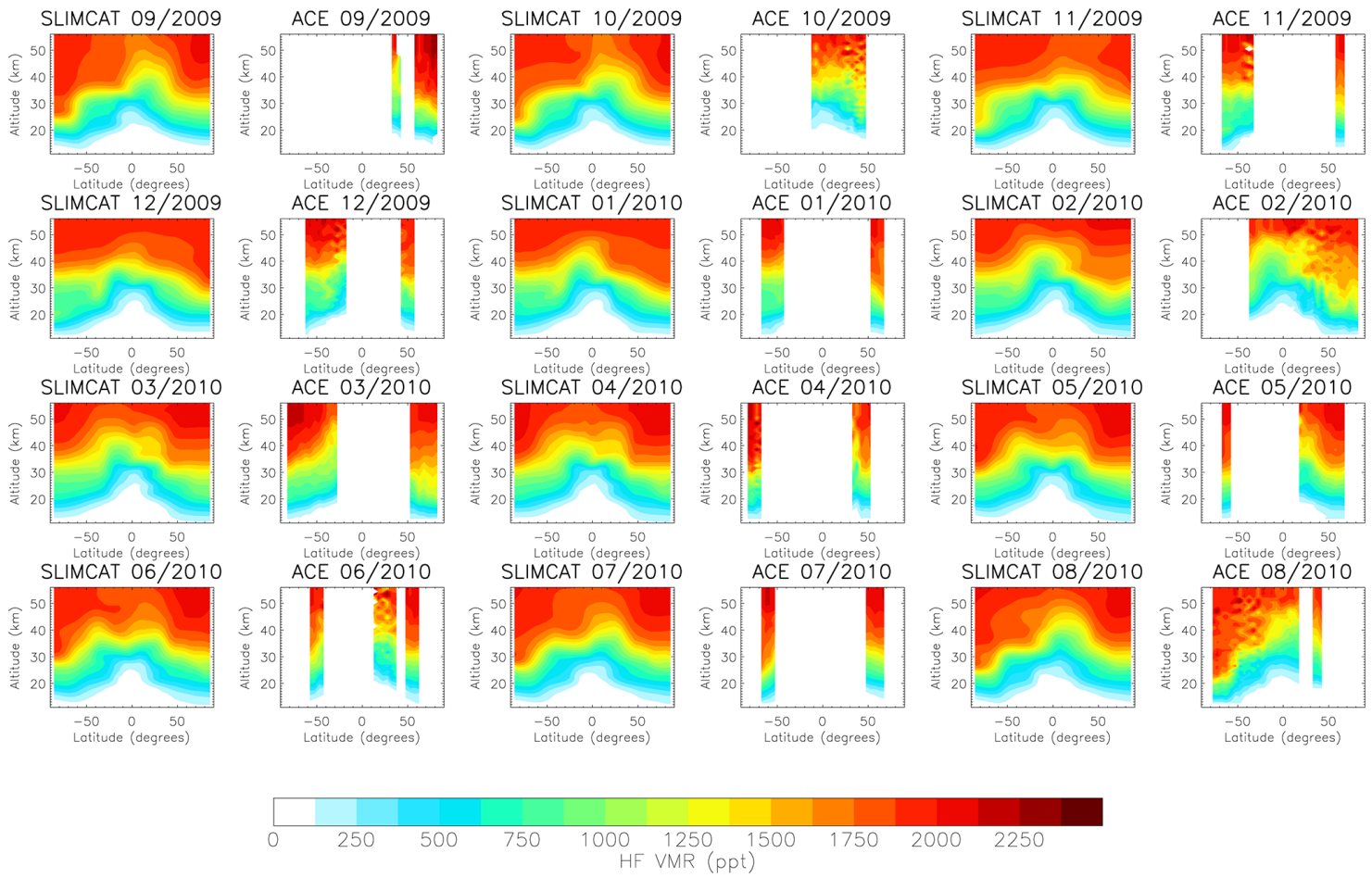

Figure 1. A comparison between ACE-FTS and SLIMCAT HF zonal means (September 2009 to August 2010). A full discussion of the seasonal variation in the HF distribution is provided in the text.

good agreement between the ACE-FTS observations and the model, which reproduces very well the significant seasonal variation. For example, note in particular the agreement for regions of low HF VMR $(<1000 \mathrm{ppt})$ at $\sim 30-40 \mathrm{~km}$ over the southern tropics in February 2010 and the northern tropics in August 2010, at southern middle to high latitudes in December 2009 and March and August 2010, and at northern middle to high latitudes in February and March 2010.

Plots of ACE-FTS and HALOE HF observations side by side with SLIMCAT HF calculations for September 2004 to August 2005 are shown in Fig. 2. As for Fig. 1, the agreement between observations and model is generally good and the significant seasonal variation is well reproduced. Note that, as for the ACE-FTS, HALOE data do not cover all latitude bins in a given month, although HALOE does take more measurements at lower latitudes. One noticeable difference revealed in Fig. 2 is the relative low bias of HALOE measurements compared with ACE-FTS and SLIMCAT; this is most notable at the top of the altitude range. Using the period of overlap between ACE and HALOE, we can estimate that ACE v3.0 is biased high by about $10 \%$ relative to HALOE. Biases between observations and SLIMCAT will be more fully addressed in Sect. 6.

The overall atmospheric distribution of HF is determined by a complicated combination of its production and transport, which depends on the production and lifetimes of its "sources" $\mathrm{COF}_{2}$ and $\mathrm{COClF}$. Figure 3 shows the observed and modelled $\mathrm{COF}_{2}$ and $\mathrm{COClF}$ zonal means for October 2009 and February and August 2010. Due to the upwelling of relatively organic-fluorine-rich air in the tropical regions, the largest VMRs of $\mathrm{COF}_{2}$ and $\mathrm{COClF}$ are found over the tropics (Harrison et al., 2014; Fu et al., 2009), where solar insolation is highest due to the small solar zenith angle, at altitudes of $\sim 30-40$ and $\sim 25-30 \mathrm{~km}$, respectively. For $\mathrm{COF}_{2}$ the model agrees well with the ACE observations in terms of magnitude and spatial distribution. For CO$\mathrm{CIF}$ the modelled distribution agrees with ACE but the peak VMR is overestimated. Analysis of the SLIMCAT simulation shows that there is net loss of $\mathrm{COF}_{2}$ and $\mathrm{COClF}$ at altitudes above those of the maximum VMRs, at all locations. There is therefore a correlation between the stratospheric regions of low HF VMR $(<1000 \mathrm{ppt})$ above $\sim 20 \mathrm{~km}$ at the poles and $\sim 25 \mathrm{~km}$ at the Equator and those of peak $\mathrm{COF}_{2}$ and $\mathrm{COClF}$ VMRs.

Figure 1 reveals an asymmetry in the seasonal $\mathrm{HF}$ distribution between the two hemispheres. This is attributable to asymmetries in the distributions of the "sources" $\mathrm{COF}_{2} / \mathrm{COClF}$ and their precursors, due to differences in the meridional Brewer-Dobson circulation, and to the stronger descent of air associated with the winter polar vortex in the Southern Hemisphere; for example, compare the enhanced ACE-FTS HF VMRs near the South Pole in August 2010 with those near the North Pole in February 2010 at $\sim 25 \mathrm{~km}$. An additional source of asymmetry in the $\mathrm{COF}_{2}$ distribution, 

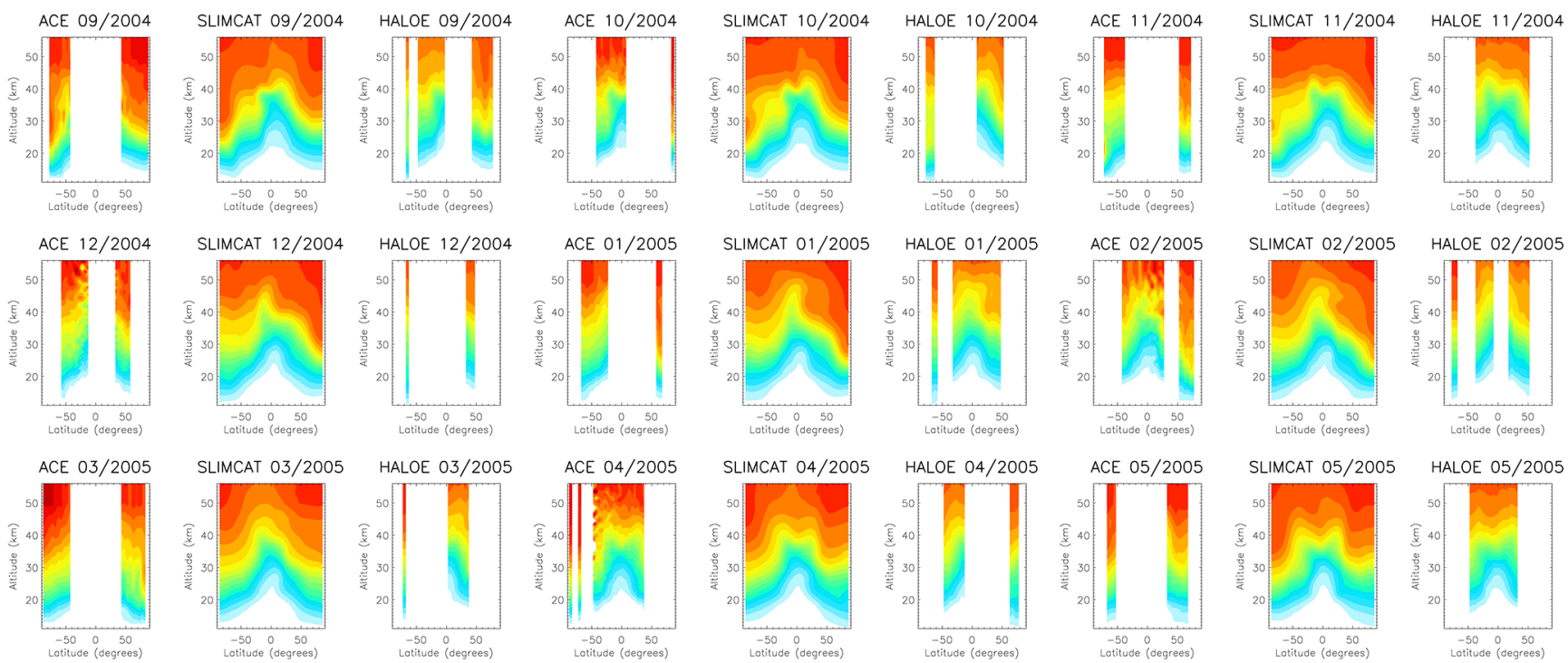

SLIMCAT 04/2005

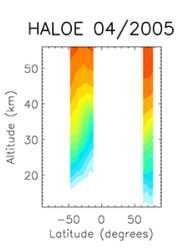

ACE 05/2005

SLIMCAT 05/2005

HALOE 05/2005
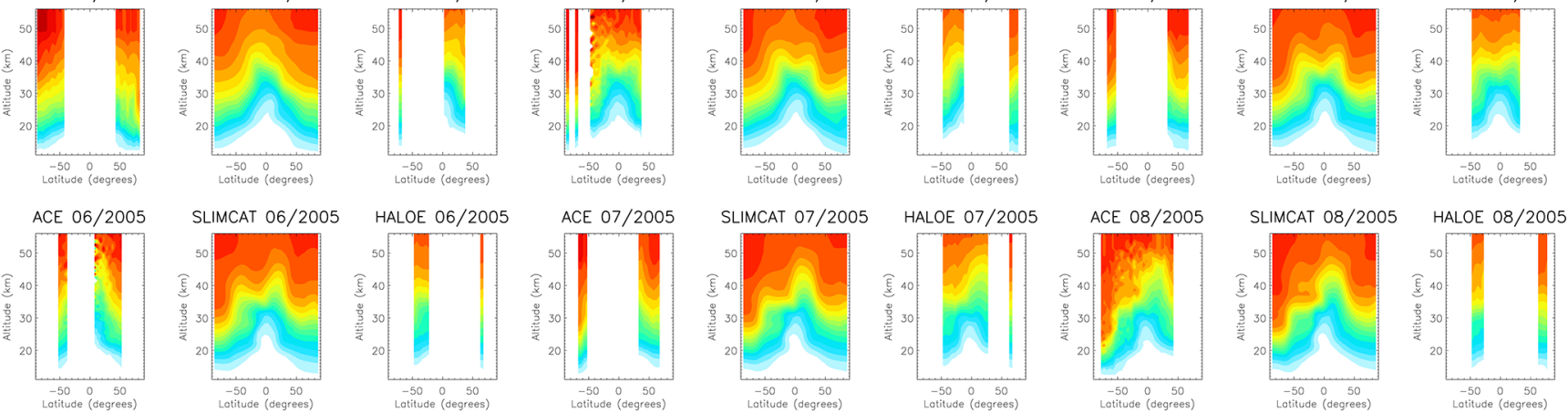

SLIMCAT 07/2005 HALOE 07/2005
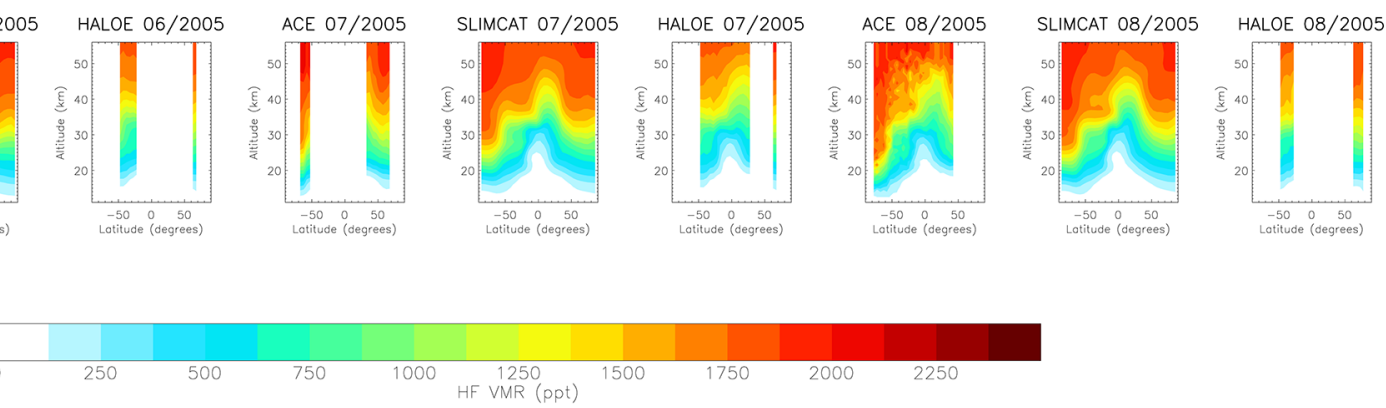

Figure 2. A comparison between ACE-FTS, HALOE, and SLIMCAT HF zonal means (September 2004 to August 2005). The ACE-FTS and HALOE time series of measurements overlap during the period January 2004 to November 2005.

which directly influences the HF distribution, arises from the temperature-dependent loss reaction of the $\mathrm{COF}_{2}$-precursor $\mathrm{CHClF}_{2}$ (HCFC-22) with $\mathrm{OH}$, leading to a secondary $\mathrm{COF}_{2}$ maximum at southern hemispheric high latitudes in the summer mid-stratosphere $(\sim 10 \mathrm{~K}$ warmer than the corresponding location in the Northern Hemisphere) (Harrison et al., 2014); for example, compare the ACE-FTS HF southern hemispheric VMRs at $\sim 30-35 \mathrm{~km}$ in January 2010 with those in the Northern Hemisphere in July 2010.

In addition to side-by-side comparisons of model and observation, the chemistry scheme in SLIMCAT can be tested by comparing (chemically related) tracer-tracer correlations for model and observation; only ACE measurements of fluorine-containing HF "precursors" are available for this purpose. It is widely known that all long-lived species in the stratosphere have compact correlations, even when there is no chemical link between them. As explained by Plumb and Ko (1992), two tracers with lifetimes longer than quasihorizontal mixing timescales should be in "slope equilibrium" and produce a compact correlation. Species with lifetimes longer than vertical transport timescales will also be in "gradient equilibrium" and the compact correlation will be linear. Furthermore, relative lower-stratospheric lifetimes of long-lived species (with stratospheric sinks via photolysis or reaction with $\mathrm{O}\left({ }^{1} \mathrm{D}\right)$ ) under gradient equilibrium can be derived from the linear slope of the tracer-tracer correlation (Chipperfield et al., 2014).

In the lower stratosphere $\mathrm{COF}_{2}$ and $\mathrm{COClF}$ can be regarded as long-lived tracers (local lifetimes of many years). Therefore, their tracer isopleths should follow the typical tropopause-following contours of any long-lived tracer. In this sense, $\mathrm{COF}_{2}$ and $\mathrm{COClF}$ are analogous to $\mathrm{NO}_{y}$, which is produced from $\mathrm{N}_{2} \mathrm{O}$. Figure 4 contains correlation plots between $\mathrm{COF}_{2}$ and its major source, $\mathrm{CFC}-12$, over the two latitude bands $65-70^{\circ} \mathrm{S}$ and $65-70^{\circ} \mathrm{N}$ for 2 months each over the period September 2009-August 2010. Comparisons are made at high latitudes, where ACE-FTS observations are more plentiful, and for individual months to ensure that time trends in the source-gas VMRs are minimised. The figure reveals that $\mathrm{COF}_{2}$ is indeed long-lived enough to show a good anti-correlation with CFC-12 in the lower stratosphere. Furthermore, agreement between the model and observations is good although there are a few discrepancies around the region of maximum $\mathrm{COF}_{2} \mathrm{VMR}$; these are due to issues sur- 

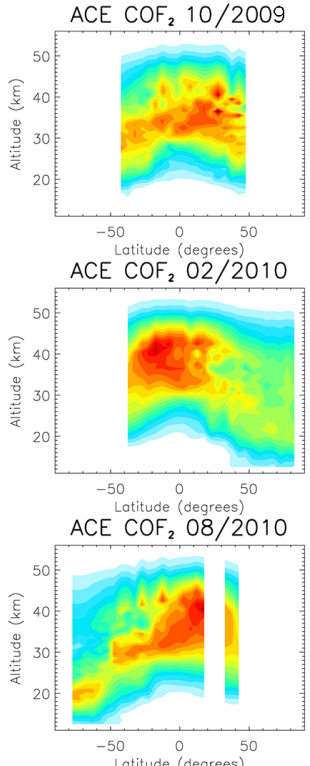
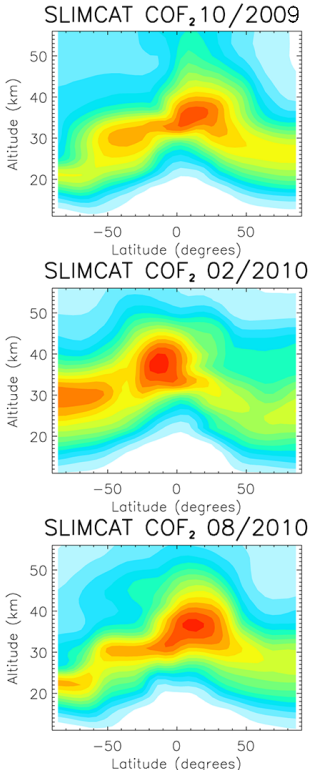
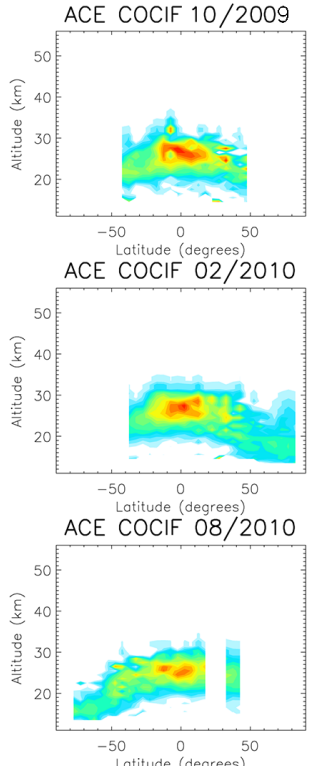
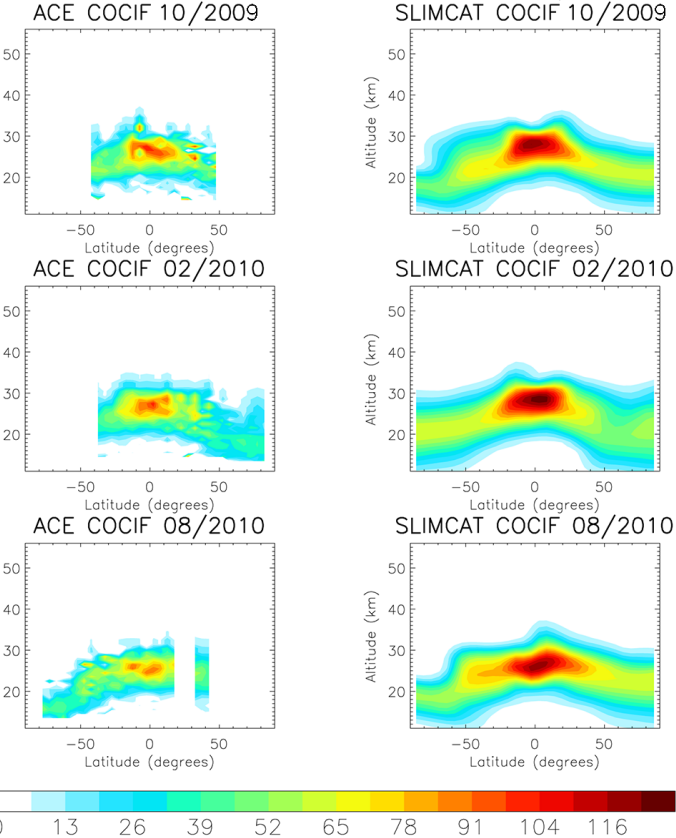

Figure 3. A comparison of $\mathrm{COF}_{2}$ and COCIF zonal means from ACE-FTS and SLIMCAT for October 2009 and February and August 2010.
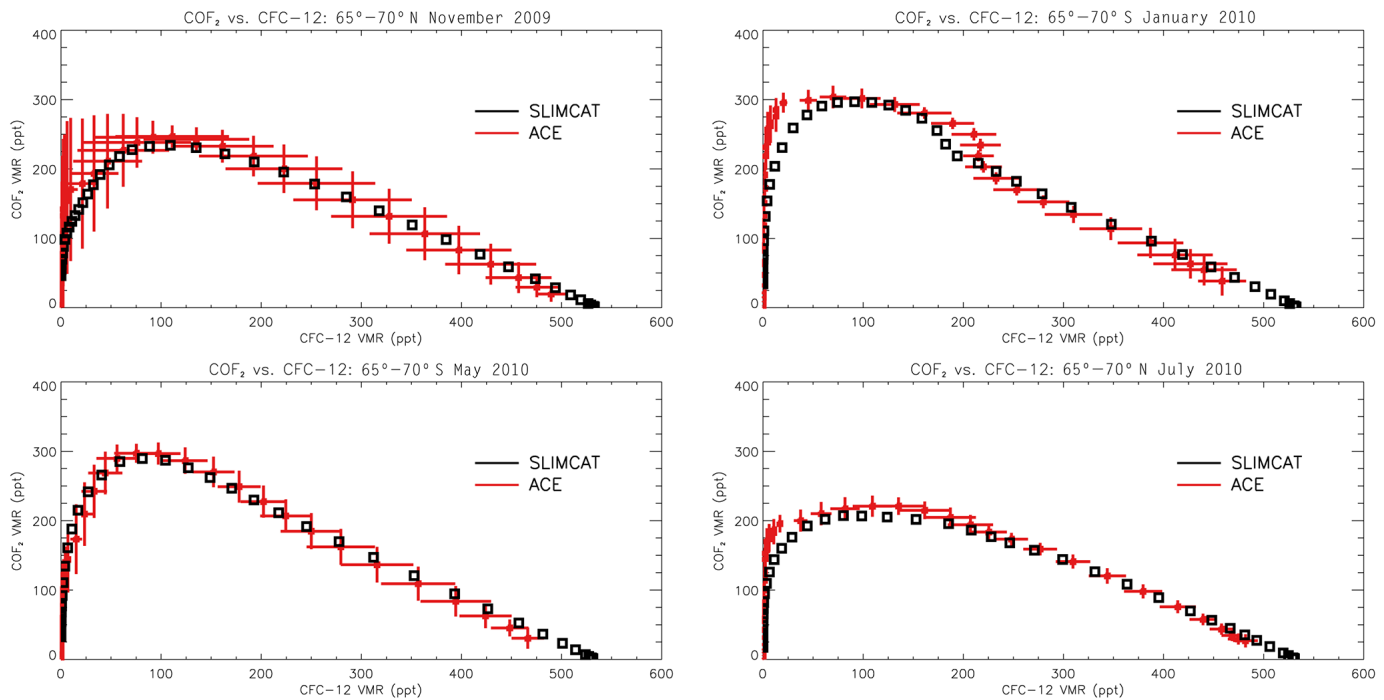

Figure 4. Correlation plots between coincident CFC-12 and $\mathrm{COF}_{2}$ ACE-FTS observations and SLIMCAT calculations for November $2009 /$ July $201065-70^{\circ} \mathrm{S}$ and January/May $201065-70^{\circ} \mathrm{N}$. The error bars represent the standard deviations in the ACE-FTS VMRs.

rounding the scaled a priori used in the retrieval for this altitude region of the profile where the spectral signal has dropped to within the noise level (refer to Harrison et al., 2014, for more details).

Figure 5 contains correlation plots between $\mathrm{COClF}$ and its major source, $\mathrm{CFC}-11$, for the same conditions as in Fig. 4. Unlike for $\mathrm{COF}_{2} / \mathrm{CFC}-12$, the agreement between model and ACE-FTS is particularly poor and the model overestimates the peak observed values of COClF; this can also be ob- served in Fig. 3. There are several possible reasons for this. Firstly, as the modelled VMRs are $\sim 50 \%$ higher than the ACE-FTS VMRs, the modelled COCIF lifetime might be too long, i.e. the model underestimates the COClF loss processes. This would result in the calculated HF VMRs being slightly lower than they should be, probably by less than a percent, but certainly by less than the uncertainty of the ACE-FTS measurements. An additional SLIMCAT calculation with the COClF lifetime lowered by a third does im- 

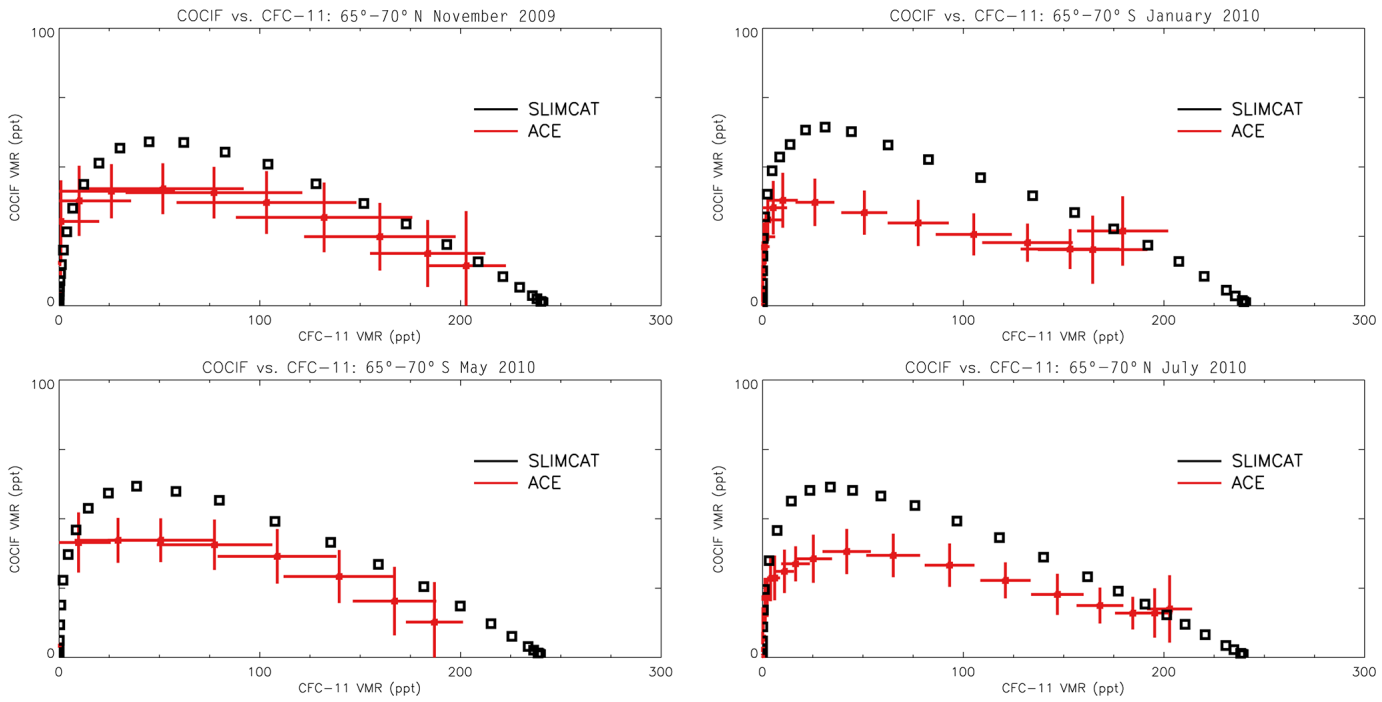

Figure 5. Correlation plots between coincident CFC-11 and COCIF ACE-FTS observations and SLIMCAT calculations for November $2009 /$ July $201065-70^{\circ} \mathrm{S}$ and January/May $201065-70^{\circ} \mathrm{N}$. The error bars represent the standard deviations in the ACE-FTS VMRs.
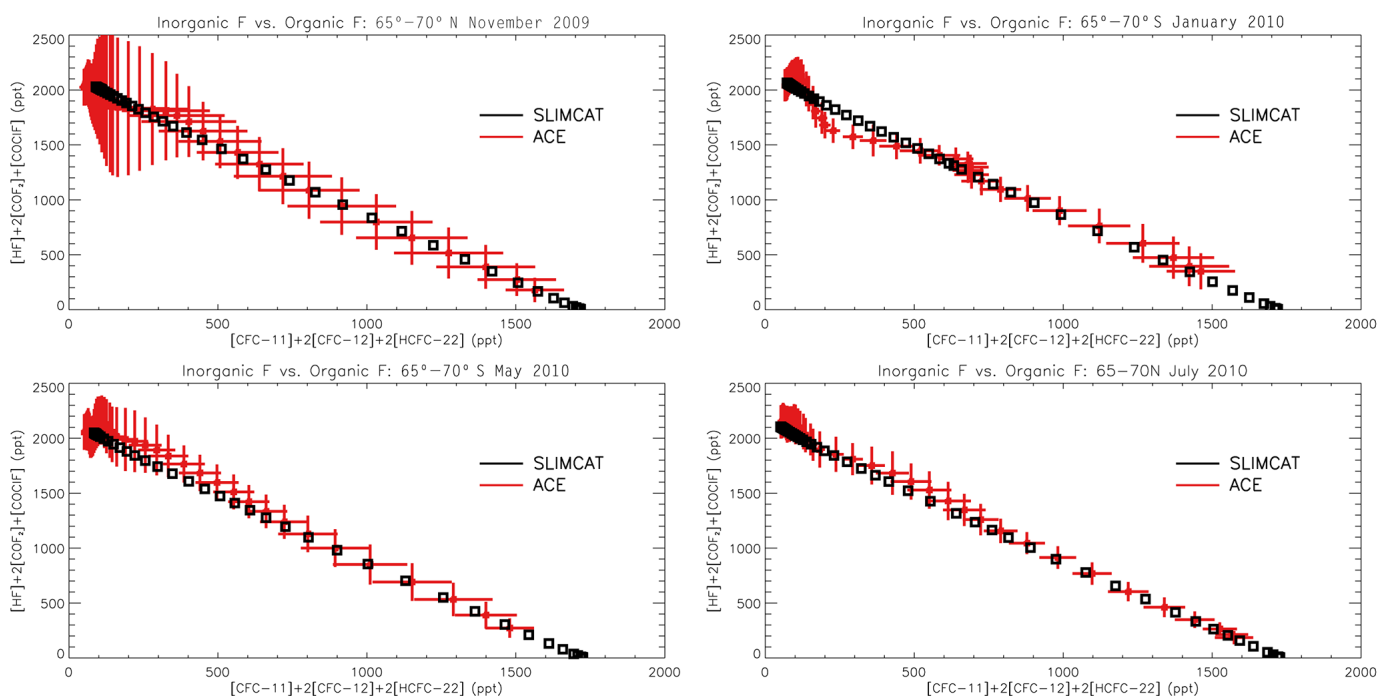

Figure 6. Correlation plots between coincident ACE-FTS observations and SLIMCAT calculations of total "major" organic fluorine, based on CFC-11, CFC-12, and HCFC-22, and total inorganic fluorine, $\mathrm{F}_{y}$, for November 2009/July $201065-70^{\circ} \mathrm{S}$ and January/May $201065-70^{\circ} \mathrm{N}$. The error bars represent the standard deviations in the ACE-FTS VMRs.

prove the agreement with observations. Secondly, the CO$\mathrm{ClF}$ sources might be overestimated, but SLIMCAT calculations for CFC-11 reveal good agreement with ACE-FTS observations, generally within $10 \%$ (Brown et al., 2011). Additionally, the chemistry could be more complicated with additional destruction routes missing from the model. Lastly, there could be a problem with the ACE-FTS retrieval itself. The COCIF line list used in the ACE-FTS retrieval was taken from the ATMOS database and is described in the literature as "very crude" (Perrin et al., 2011). At the time v3.0 data were first released, this was the best line list available, but a new and improved line list has subsequently been generated (Perrin et al., 2011), in which the band intensities are taken from quantum-mechanical calculations. ACE-FTS $\mathrm{COClF}$ retrievals for a handful of occultations have been carried out using the new line list, but there is no improvement in the disagreement with SLIMCAT.

It is expected that the sum of all fluorine source-gas VMRs (not including those which have very long lifetimes compared with the period of observations, e.g. $\mathrm{CF}_{4}$ and $\mathrm{SF}_{6}$ ) is anti-correlated with total $\mathrm{F}_{y} \mathrm{VMR}\left(\mathrm{HF}+2 \mathrm{COF}_{2}+\mathrm{COClF}\right)$ in a conservative way (i.e. the total adds up to a constant). As 

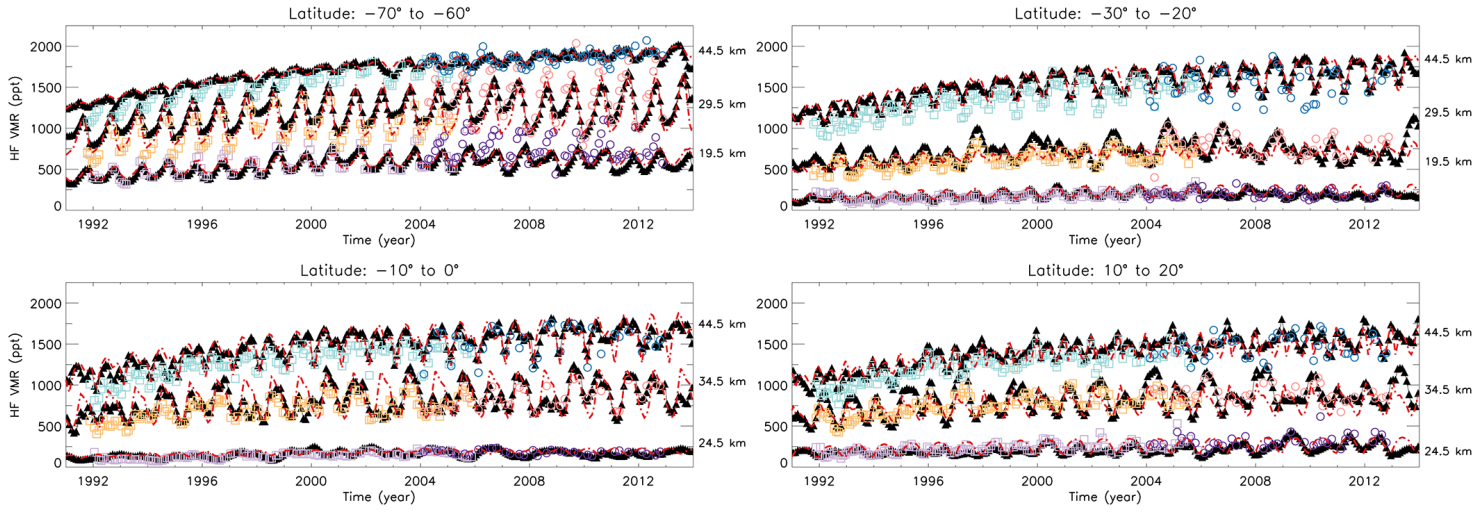

Latitude: $30^{\circ}$ to $40^{\circ}$

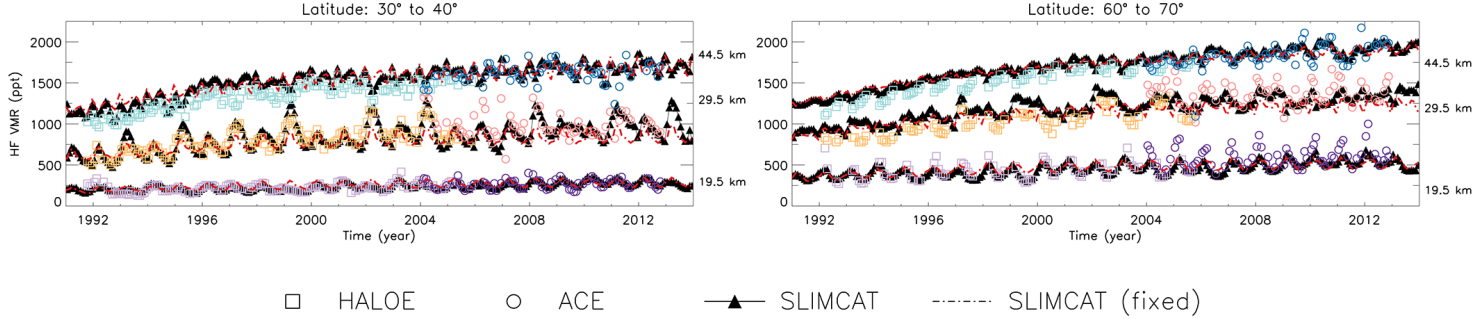

Figure 7. The HALOE, ACE-FTS, and SLIMCAT HF time series for selected altitude-latitude bin combinations. Observations are plotted between October 1991 and December 2012. Overlaid are the time series from a SLIMCAT run with dynamics arbitrarily annually repeating those for the year 2000; this provides a clearer signal of the long-term chemical changes without the complication of variations in stratospheric dynamics.

the ACE-FTS does not measure every source gas, and some minor species have known biases (Brown et al., 2011), we only compare total $\mathrm{F}_{y}$ against the sum of the major source gases, taken as CFC-11, CFC-12, and HCFC-22. The good agreement between plots for SLIMCAT and ACE-FTS (see Fig. 6) confirms that the discrepancy in modelled and retrieved COClF VMRs has a minimal effect on the overall agreement between model and observation for HF.

\section{Trends}

Since HF has no chemical sink, with only minor losses arising from rainout in the troposphere and photolysis in the mesosphere, and since the atmosphere contains many long-lived fluorine source gases, the overall HF atmospheric abundance has been increasing for many years and is expected to increase in the foreseeable future. In this section trends in ACE-FTS, HALOE, GOZCARDS, and SLIMCAT time series are quantified as a function of altitude and latitude. A number of previous studies have quantified trends; for example, a linear trend of $8.5 \pm 1.0 \%$ year $^{-1}$ (1977 to 1986) (Zander et al., 1987) and $0.48 \pm 0.25 \%$ year $^{-1}$ (2000 to 2009) (Kohlhepp et al., 2012) in total columns measured at Jungfraujoch $\left(46.5^{\circ} \mathrm{N}\right.$ latitude, $8.0^{\circ} \mathrm{E}$ longitude $)$ and $0.74 \pm 0.2 \%$ year $^{-1}$ (between $30^{\circ} \mathrm{S}$ and $30^{\circ} \mathrm{N}$ ) derived from ACE-FTS data for 2004 to 2010 (Brown et al., 2011).
Prior to the calculation of ACE-FTS, HALOE, and SLIMCAT trends, we derived time series as a function of altitude (on the ACE-FTS grid) and latitude (in $10^{\circ}$ bins). Figure 7 illustrates the ACE-FTS, HALOE, and SLIMCAT time series for HF between 1991 and 2013 at selected altitudes for six of the latitude bins; for ease of viewing, error bars are not shown. The annual cycle is clearly visible in each time series, a result of the seasonality of the main "source", $\mathrm{COF}_{2}$ (Harrison et al., 2014), and careful inspection of Fig. 7 reveals that as expected the phase of this cycle is opposite in each hemisphere. The amplitude is largest at high southern latitudes (note the maxima at $29.5 \mathrm{~km}$ for the $60-70^{\circ} \mathrm{S}$ plot) due to the descent of HF-rich air in southern winter polar vortices. Note also evidence of the quasi-biennial oscillation signal in the tropical plots.

Overall the agreement between SLIMCAT and observations presented in Fig. 7 is good, but obvious biases are present. In Sect. 5 it was discussed that ACE v3.0 is biased high relative to HALOE by $\sim 10 \%$. HALOE VMRs are biased low relative to SLIMCAT, generally by between $\sim 5$ and $15 \%$, although SLIMCAT is biased low relative to HALOE by up to $\sim 20 \%$ between $\sim 20$ and $30 \mathrm{~km}$ in the $0-30^{\circ} \mathrm{N}$ region. Additionally, there is a discrepancy in the observed and calculated annual cycle structure over the tropics, e.g. 10$20^{\circ} \mathrm{N}$ at $34.5 \mathrm{~km}$. In terms of bias, ACE-FTS v3.0/3.5 data generally agree with SLIMCAT to within $\pm 5 \%$, except over much of the lower stratosphere (below $30 \mathrm{~km}$ ) where SLIMCAT is biased low by at least $\sim 5-15 \%$, peaking at $\sim 20 \%$ in 

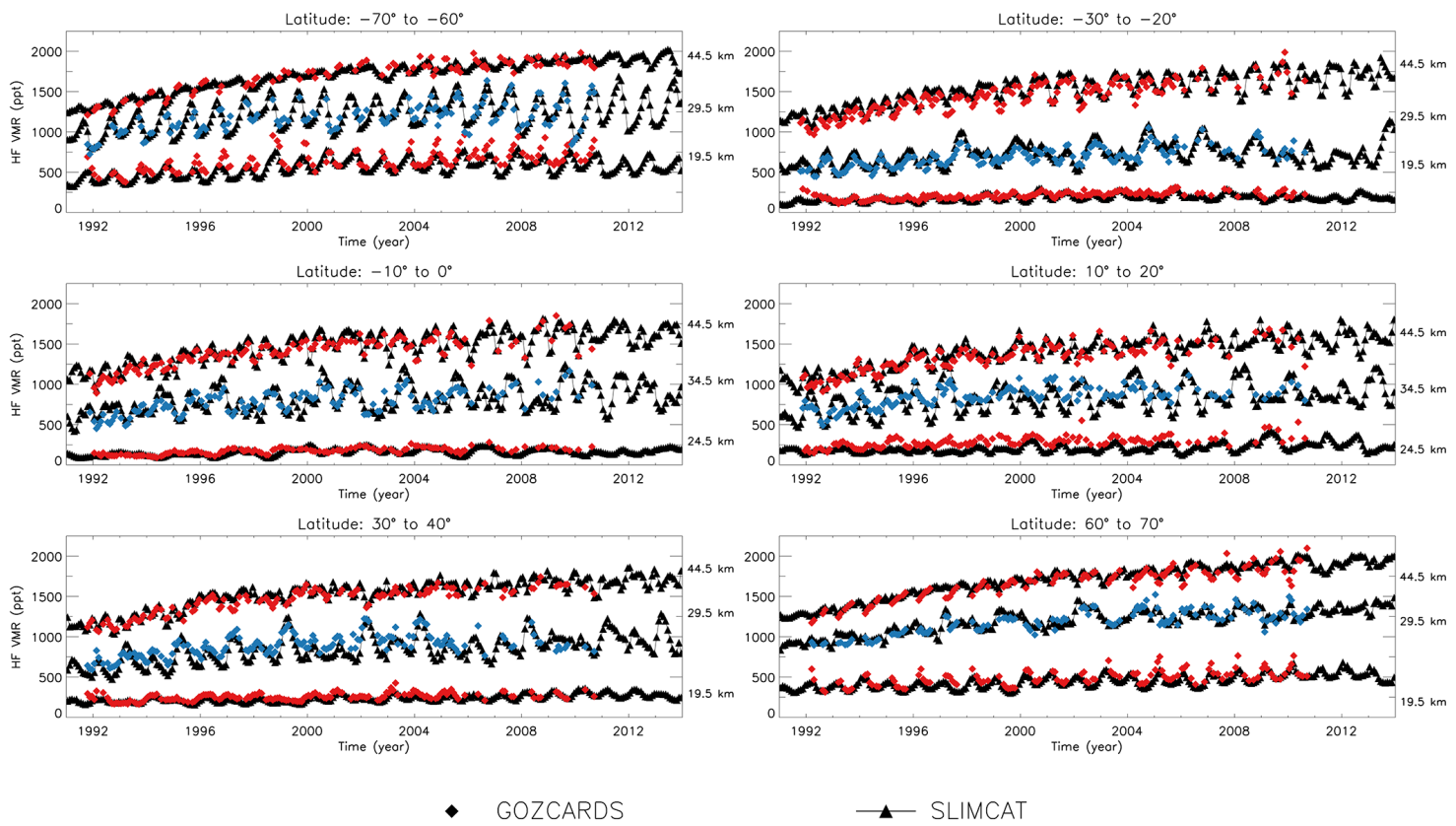

Figure 8. The GOZCARDS and SLIMCAT HF time series for selected altitude-latitude bin combinations. Observations are plotted between October 1991 and September 2010.

the $0-30^{\circ} \mathrm{N}$ region and $\sim 25-35 \%$ at the southern and northern high latitudes (poleward of $50^{\circ}$ ).

Figure 8 illustrates the GOZCARDS and SLIMCAT time series for HF plotted in the same manner as Fig. 7. Recall that the GOZCARDS HF data product is a merging of the HALOE v19 and ACE-FTS v2.2 HF datasets, with the relative bias between the datasets removed. The agreement between SLIMCAT and the HALOE component of GOZCARDS above $\sim 30 \mathrm{~km}$ is reasonably good; however, at lower altitudes there are several regions in which the low bias of SLIMCAT is significantly larger than presented in Fig. 7, in particular below $20 \mathrm{~km}$ near the South Pole and between $\sim 20$ and $30 \mathrm{~km}$ in the Northern Hemisphere, where the bias peaks at $\sim 35 \%$ in the $0-30^{\circ} \mathrm{N}$ region. The ACE-FTS component of GOZCARDS generally agrees with SLIMCAT to within $\pm 5 \%$ above $30 \mathrm{~km}$ at the tropics and above $25 \mathrm{~km}$ in the polar regions. At altitudes lower than these SLIMCAT is biased low, for example by $\sim 5-10 \%$ at latitudes above $50^{\circ} \mathrm{N}$ and up to $25 \%$ lower between 20 and $30 \mathrm{~km}$ in the $0-30^{\circ} \mathrm{N}$ region.

The GOZCARDS merging process for HF relied only on the relative bias between the HALOE v19 HF and ACE-FTS v2.2 HF datasets. In this study, it is not possible to comment on systematic or absolute biases. However, regardless of the absolute biases of the various datasets, it is clear that SLIMCAT tends to consistently underestimate HF VMRs at low altitudes (below $30 \mathrm{~km}$ at the tropics and $25 \mathrm{~km}$ at the poles) relative to those at higher altitudes.

HF trends for the ACE-FTS, HALOE, and SLIMCAT time series (trends were not considered for GOZCARDS as this is a merged dataset directly related in a multiplicative fashion to the original datasets) at each altitude within each latitude bin have been calculated for three time periods from monthly percentage anomalies in $\mathrm{HF}$ zonal means, $C^{z, \theta}(n)$, defined as

$$
C^{z, \theta}(n)=100 \frac{\mathrm{VMR}^{z, \theta}(n)-\sum_{m=1}^{12} \delta_{n m} \overline{\operatorname{VMR}}^{z, \theta}(m)}{\sum_{m=1}^{12} \delta_{n m} \overline{\operatorname{VMR}}^{z, \theta}(m)},
$$

where $n$ is a running index from month zero to month $n-1$, $\mathrm{VMR}^{z, \theta}(n)$ is the corresponding mixing ratio at altitude $z$ and latitude $\theta, \overline{\mathrm{VMR}}^{z, \theta}(m)$ is the average of all zonal means for each of the 12 months, $m$, and $\delta_{n m}$, although not used in its strict mathematical sense, is 1 when index $n$ corresponds to one of the months $m$ and is 0 otherwise (Harrison et al., 2014). Such an approach essentially removes the annual cycle and the effect of biases in VMRs; the trend, in units of $\%$ year $^{-1}$, is simply equated to the "slope" of the linear regression between $C^{z, \theta}(n)$ and the dependent variable $n / 12$. The inclusion of additional terms such as the annual cycle and its harmonics resulted in no additional improvement in the regression. The three time periods considered are January 2004 to December 2012 (ACE-FTS, SLIMCAT), October 1991 to December 1997 (HALOE, SLIMCAT), and January 1998 to November 2005 (HALOE, SLIMCAT). The HALOE time series was split into two periods for which HF growth could be modelled linearly. Errors have been explicitly treated in the linear regression of the ACE and HALOE data, but not the SLIMCAT outputs. 

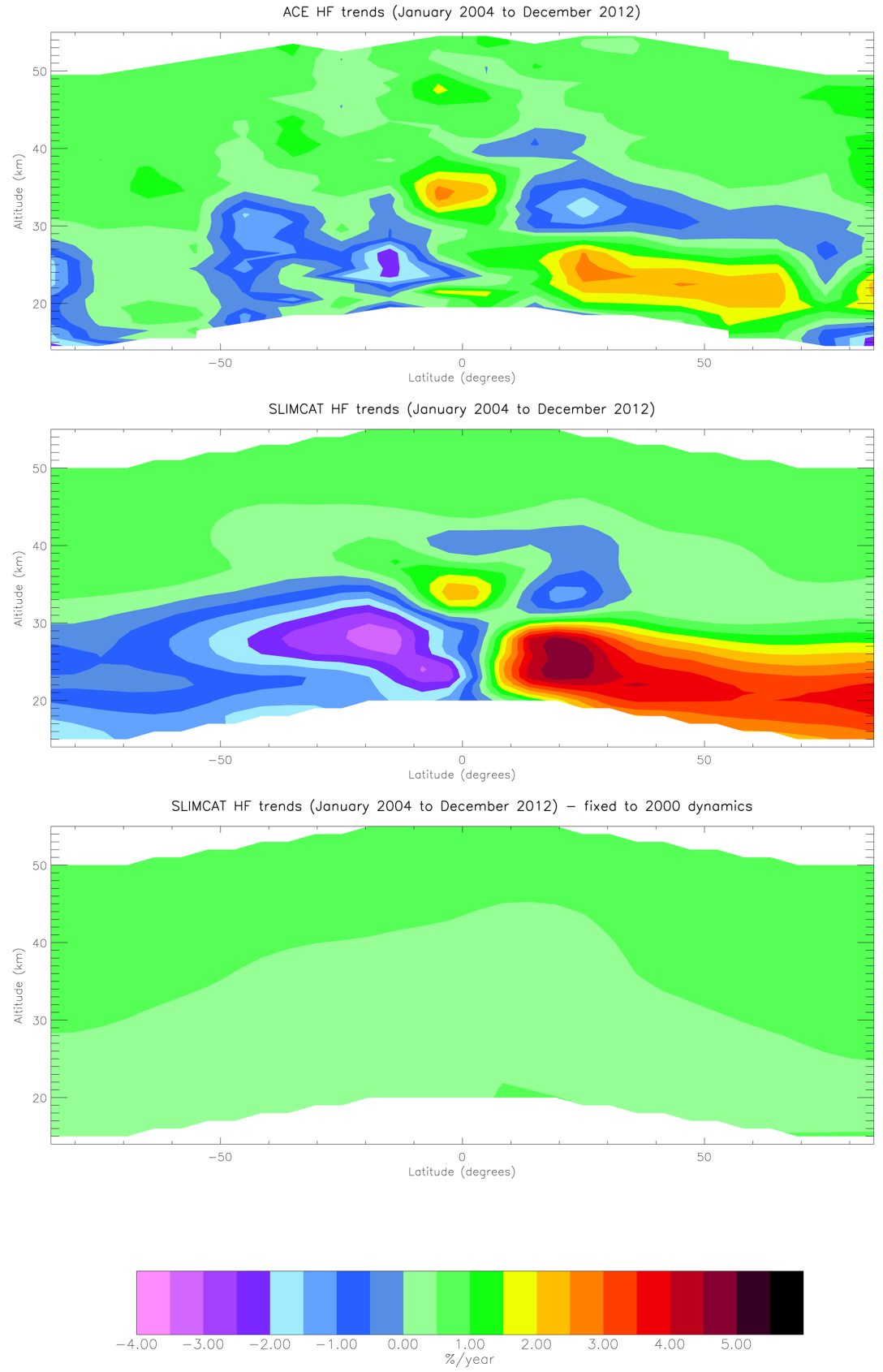

Figure 9. Trends in the growth of HF (\% year ${ }^{-1}$; January 2004 to December 2012) for ACE-FTS and SLIMCAT as a function of latitude and altitude. A full discussion of these trends is provided in the text.

Figure 9 presents the trends in the growth of HF (percent per year) (January 2004 to December 2012) for ACE and SLIMCAT as a function of latitude and altitude, up to the top of the ACE-FTS retrieval range. The ACE-FTS plot in Fig. 9 indicates that between 2004 and 2012, HF has increased most rapidly $\left(2-3 \%\right.$ year $\left.^{-1}\right)$ at altitudes below $\sim 25 \mathrm{~km}$ in the Northern Hemisphere and at $\sim 35 \mathrm{~km}$ near the Equator. Similarly, HF has decreased most rapidly in the Southern Hemisphere below $\sim 35 \mathrm{~km}$ and in the Northern Hemisphere between $\sim 30$ and $35 \mathrm{~km}$. The SLIMCAT plot in the second panel contains a number of features which agree well with those in the ACE plot. In particular, note the region of negative trends in the Southern Hemisphere below $~ 30-35 \mathrm{~km}$, peaking at -3.5 to $-4.0 \%$ year $^{-1}$, the region of high positive trends in the Northern Hemisphere below $\sim 30 \mathrm{~km}$, peaking at $4.5-5.0 \%$ year $^{-1}$, the small region of positive trend at $\sim 35 \mathrm{~km}$ near the Equator, peaking at $2.0-2.5 \%$ year $^{-1}$, and the slightly larger region of negative trend at $\sim 30-40 \mathrm{~km}$ at 
0 to $30^{\circ} \mathrm{N}$, peaking at -1.0 to $-1.5 \%$ year $^{-1}$. However, the magnitudes of the SLIMCAT trends in the lower stratosphere are biased high compared with the ACE measurements.

An additional SLIMCAT run has been performed with dynamics arbitrarily annually repeating those for the year 2000; results from this run give a "clean" HF signal without the complication of changes in stratospheric dynamics. Results from this run are included in the times series plots in Fig. 7; the annual repetition in dynamical structure reveals a clearer signal of the long-term chemical changes. "Clean" HF trends for 2004-2012 calculated in the same manner as before are plotted in the lowest panel of Fig. 9, revealing trends distributed relatively uniformly throughout the stratosphere with values between 0 and $1 \%$ year $^{-1}$. This indicates that the variations in trends observed for the full SLIMCAT run result from changes in stratospheric dynamics over the observation period. The information on stratospheric circulation is provided solely by the analyses used to force the SLIMCAT calculations. Similar changes due to stratospheric dynamics were observed for $\mathrm{COF}_{2}$ (Harrison et al., 2014). Moreover, Ploeger et al. (2015) used a Lagrangian chemical transport model, also forced by ECMWF ERA-Interim reanalyses, to look at variations in stratospheric age-of-air (AoA) over the period 1988-2013. They compared their model results with estimates derived from MIPAS satellite observations for 2002-2012. During the period of MIPAS observations they found that stratospheric AoA decreased in the lower stratosphere but showed interhemispheric differences in the trend above about $20 \mathrm{~km}$. Also, despite the ongoing monotonic decrease of near-surface chlorine source gases, recent ground-based and satellite remote-sensing measurements have shown a significant increase in hydrogen chloride $(\mathrm{HCl})$, the main stratospheric chlorine reservoir, in the lower stratosphere of the Northern Hemisphere between 2007 and 2011 (Mahieu et al., 2014). By comparison to similar SLIMCAT simulations as used here, this trend "anomaly" was attributed to multiyear variability in the stratospheric circulation and dynamics.

Together, the studies discussed above paint a consistent picture whereby variability in stratospheric transport, which varies with altitude and hemisphere, significantly modifies the observed trends in long-lived tracers. This variability seems to be well captured by reanalysis products such as ERA-Interim. Even if these tracers have monotonic VMR trends in the troposphere, this dynamical variability can lead to complicated behaviour in the stratosphere and must therefore be accounted for when using observations to determine underlying chemical trends. A detailed analysis of the changing stratospheric dynamics that are responsible for the observed trends in HF and other species is beyond the scope of this work and would require a coupled chemical-dynamical model.

Trends have similarly been derived for the two HALOE periods. HALOE plots corresponding to the ACE-FTS plots in Fig. 9 can be found in Figs. 10 (1991-1997) and 11 (1998-
Table 5. Trends $\left(\%\right.$ year $\left.^{-1}\right)$ derived from the HALOE v19 and ACE-FTS v3.0/v3.5 HF observations.

\begin{tabular}{llrr}
\hline Dataset & \multicolumn{1}{l}{ Period } & Observed trend & SLIMCAT trend \\
\hline HALOE & $1991-1997$ & $4.97 \pm 0.12$ & 4.01 \\
HALOE & $1998-2005$ & $1.12 \pm 0.08$ & 1.10 \\
ACE-FTS & $2004-2012$ & $0.52 \pm 0.03$ & 0.48 \\
\hline
\end{tabular}

2005). The HALOE trends in Fig. 10 peaking in the Northern Hemisphere between 0 and $40^{\circ} \mathrm{N}$ broadly agree with those calculated by SLIMCAT in the same region, but SLIMCAT calculates smaller trends at the lowest altitudes and generally underestimates the trends in the Southern Hemisphere. The differences between the full and fixed-dynamics SLIMCAT runs show the impact of dynamical variability; the fixeddynamics run provides a clean chemical signal. Of the three periods considered, the comparison between 1991 and 1997 HALOE trends and those calculated from SLIMCAT is the poorest. The north-south asymmetry in trends for the full SLIMCAT calculation, which does not agree with observations, must be due to dynamical variability in the model, with the dynamics imposed solely by the ECMWF analyses. Over the measurement period, the quality of these analyses may vary depending on the available datasets used for the assimilation, but it is very difficult to test how realistic the stratospheric transport is. There are only a handful of other height-resolved datasets that test this aspect of the stratospheric circulation, e.g. ozone (Dhomse et al., 2015). As evidenced by Fig. 11, however, the HALOE trends for 1998 2005 agree better with SLIMCAT than for the 1991-1997 period, with "background" trends generally between 0.5 and $1.5 \%$ year $^{-1}$. In fact, there is very little variability over the majority of the plotted range.

Overall global trends in HF, weighted at each altitude and latitude by $\cos ^{2}\left(\right.$ latitude ${ }^{\circ}$ ) and the average VMR, have been calculated from the three time series using errors determined from the linear regression; these trends are listed in Table 5. The observed HF trends reveal a substantial slowing down in the rate of increase of HF by $\sim 90 \%$ from the mid-1990s over the next 15 years, namely from $4.97 \pm 0.12$ (19911997) to $1.12 \pm 0.08(1998-2005)$ to $0.52 \pm 0.03 \%$ year $^{-1}$ (2004-2012). In addition to direct stratospheric ozone recovery (e.g. Chipperfield et al., 2015), this marked decline in the growth rate of $\mathrm{HF}$ is a particularly important marker for the success of the Montreal Protocol and should drop even further once HCFC-22 is phased out in developing countries over the coming years. Global trends calculated by SLIMCAT for the HALOE (1998-2005) and ACE-FTS (2004-2012) time series, 1.10 and $0.48 \%$ year $^{-1}$, respectively, agree very well with observations; however, for the 1991-1997 HALOE period the model produces a value $\sim 20 \%$ lower $\left(4.01 \%\right.$ year $\left.^{-1}\right)$. Again, the reason for this is 

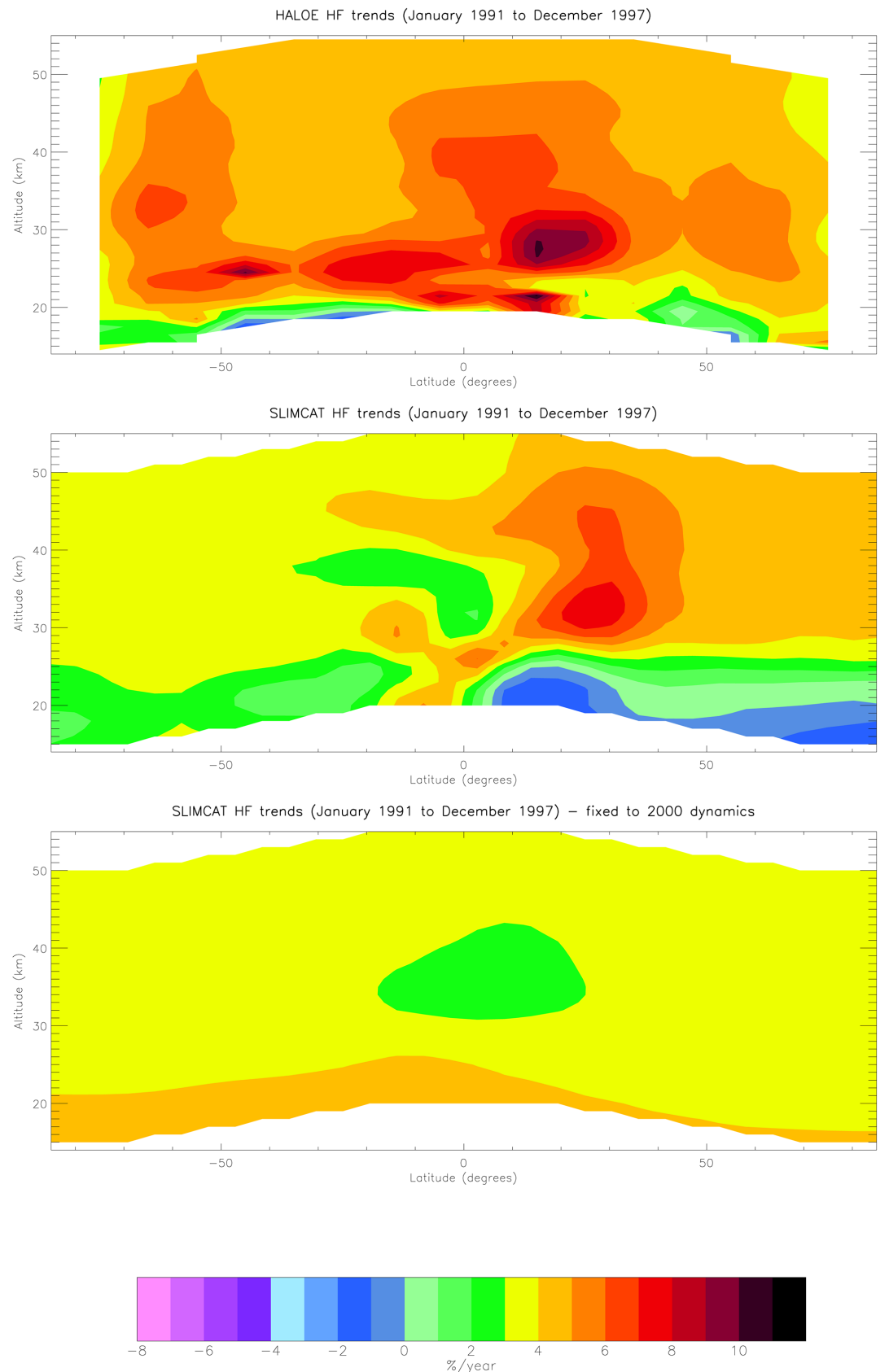

Figure 10. Trends in the growth of HF (\% year ${ }^{-1}$; October 1991 to December 1997) for HALOE and SLIMCAT as a function of latitude and altitude. A full discussion of these trends is provided in the text.

not completely clear but is likely related to the ECMWF analysis used to drive the dynamics in the SLIMCAT calculation.

\section{Conclusions}

HF is the most abundant fluorine reservoir in the stratosphere with main sources arising from the atmospheric degradation of CFC-12 $\left(\mathrm{CCl}_{2} \mathrm{~F}_{2}\right)$, CFC-11 $\left(\mathrm{CCl}_{3} \mathrm{~F}\right)$, HCFC$22\left(\mathrm{CHClF}_{2}\right)$, and $\mathrm{CFC}-113\left(\mathrm{CCl}_{2} \mathrm{FCClF}_{2}\right)$, ozone-depleting species whose emissions are anthropogenic. Monitoring the growth of stratospheric HF is therefore an important marker for the success of the Montreal Protocol.

Global distributions and trends of stratospheric HF have been determined from ACE-FTS (2004-) and HALOE (1991-2005) data. Based on the overlap period between datasets, ACE-FTS HF measurements are biased high by $\sim 10 \%$ relative to HALOE. The observations have been compared with the output of SLIMCAT, a 3-D CTM, and 

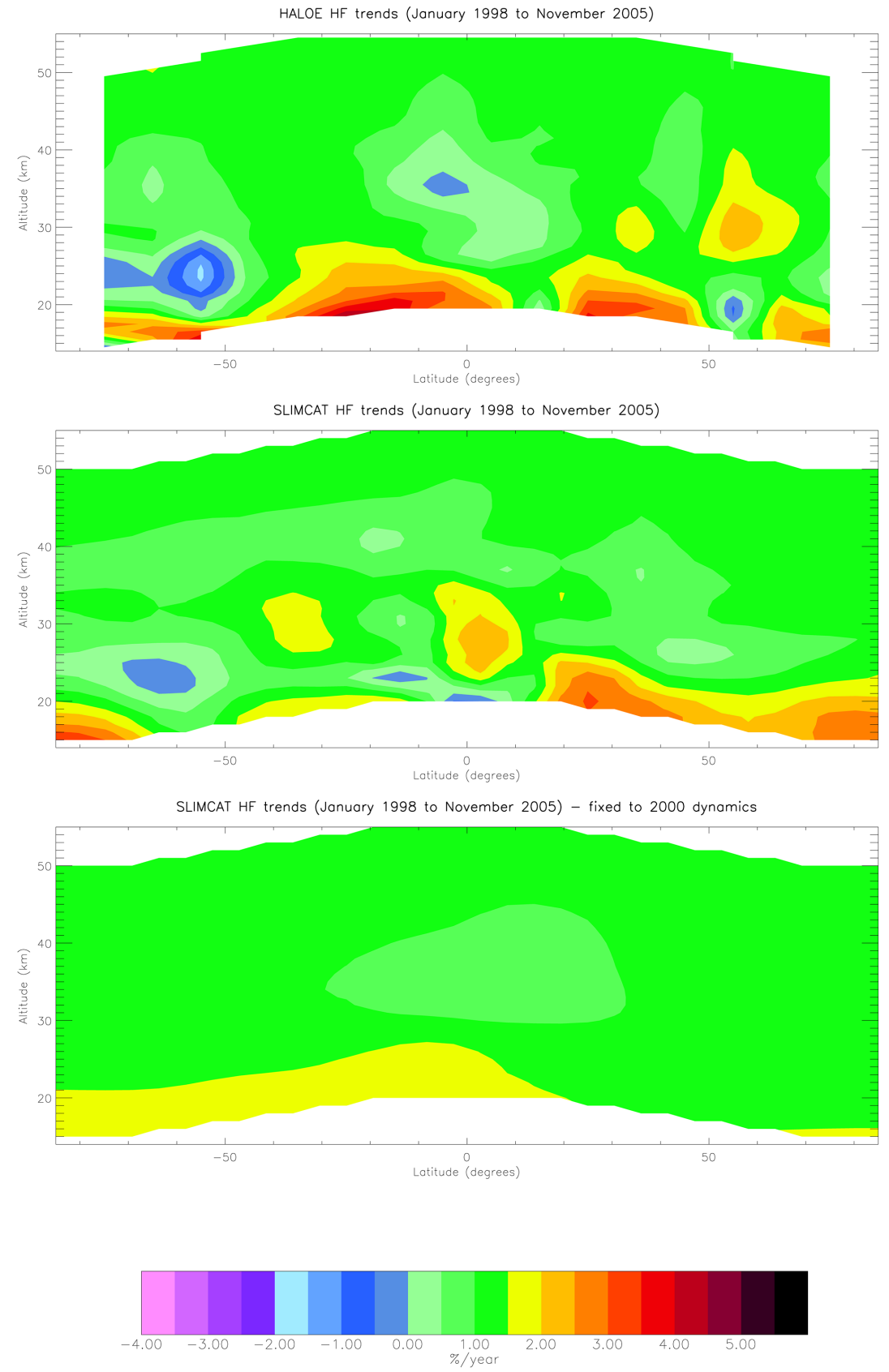

Figure 11. Trends in the growth of HF (\% year ${ }^{-1}$; January 1998 to November 2005) for HALOE and SLIMCAT as a function of latitude and altitude. A full discussion of these trends is provided in the text.

the agreement is generally good, although SLIMCAT tends to underestimate HF VMRs at low altitudes (below $30 \mathrm{~km}$ at the tropics and $25 \mathrm{~km}$ at the poles) relative to those at higher altitudes.

The observed global HF trends reveal a substantial slowing down in the rate of increase of HF since the 1990s: $4.97 \pm 0.12$ (1991-1997; HALOE), $1.12 \pm 0.08$ (1998-2005; HALOE), and $0.52 \pm 0.03 \%$ year $^{-1}(2004-2012$; ACEFTS), indicating the effectiveness of the Montreal Proto- col in phasing out the principal precursor species. For the same periods, SLIMCAT calculates trends of 4.01, 1.10, and $0.48 \%$ year $^{-1}$ respectively. The observations also reveal variations in the HF trends with latitude and altitude; for example between 2004 and 2012 HF actually decreased in the Southern Hemisphere below $\sim 35 \mathrm{~km}$. SLIMCAT calculations broadly agree with these observations, most notably between 2004 and 2012. Such variations are attributed to 
variability in stratospheric dynamics over the observation period.

The ACE-FTS is the only satellite instrument currently making measurements of $\mathrm{HF}$, and it continues to operate with only minor loss in performance since its launch. It will therefore be possible to extend the HF time series to the present day and beyond, and subsequently extend the comparison with SLIMCAT.

\section{Data availability}

ACE-FTS data were obtained from https://databace.scisat.ca/ level2/ace_v3.0/ and https://databace.scisat.ca/level2/ace_ v3.5/. HALOE data were obtained from http://haloe.gats-inc. com/home/index.php. The GOZCARDS data used in this work have not been officially released, but will become available via the GOZCARDS website (https://gozcards.jpl.nasa. gov/index.php) at a later date.

Author contributions. Jeremy J. Harrison devised the study and performed the data analysis. Christopher D. Boone and Peter F. Bernath provided the ACE-FTS data. James Russell III provided the HALOE HF data. Lucien Froidevaux and John Anderson provided the HF GOZCARDS data. Martyn P. Chipperfield and Sandip S. Dhomse ran the SLIMCAT model and provided additional explanation of the outputs. Jeremy J. Harrison prepared the manuscript with contributions from Martyn P. Chipperfield and the other co-authors.

Acknowledgements. The authors wish to thank the UK Natural Environment Research Council (NERC) for supporting Jeremy J. Harrison through grant NE/I022663/1 and through the National Centre for Earth Observation (NCEO). The ACE satellite mission is funded primarily by the Canadian Space Agency (CSA). HALOE was funded by NASA. Martyn P. Chipperfield and Sandip S. Dhomse thank Wuhu Feng (the National Centre for Atmospheric Science; NCAS) for help with SLIMCAT. Martyn P. Chipperfield is a Royal Society Wolfson Research Merit Award holder. Work at the Jet Propulsion Laboratory was performed under contract with the National Aeronautics and Space Administration (NASA). We thank the ECMWF for providing the ERA-Interim reanalyses used by the SLIMCAT model.

Edited by: R. Müller

Reviewed by: two anonymous referees

\section{References}

Bernath, P. F., McElroy, C. T., Abrams, M. C., Boone, C. D., Butler, M., Camy-Peyret, C., Carleer, M., Clerbaux, C., Coheur, P.-F., Colin, R., DeCola, P., DeMazière, M., Drummond, J. R., Dufour, D., Evans, W. F. J., Fast, H., Fussen, D., Gilbert, K., Jennings, D.E., Llewellyn, E. J., Lowe, R. P., Mahieu, E., McConnell, J. C.,
McHugh, M., McLeod, S. D., Michaud, R., Midwinter, C., Nassar, R., Nichitiu, F., Nowlan, C., Rinsland, C. P., Rochon, Y. J., Rowlands, N., Semeniuk, K., Simon, P., Skelton, R., Sloan, J. J., Soucy, M.-A., Strong, K., Tremblay, P., Turnbull, D., Walker, K. A., Walkty, I., Wardle, D. A., Wehrle, V., Zander, R., and Zou, J.: Atmospheric Chemistry Experiment (ACE): Mission overview, Geophys. Res. Lett., 32, L15S01, doi:10.1029/2005GL022386, 2005.

Boone, C. D., Walker, K. A., and Bernath, P. F.: Version 3 Retrievals for the Atmospheric Chemistry Experiment Fourier Transform Spectrometer (ACE-FTS), in: The Atmospheric Chemistry Experiment ACE at 10: A Solar Occultation Anthology, edited by: Bernath, P. F., A. Deepak Publishing, Hampton, Virginia, USA, 103-127, available at: http://www.ace.uwaterloo.ca/ publications/2013/Version3.5retreivals2013.pdf (last access: 16 August 2016), 2013.

Brown, A. T., Chipperfield, M. P., Boone, C., Wilson, C., Walker, K. A., and Bernath, P. F.: Trends in atmospheric halogen containing gases since 2004, J. Quant. Spectrosc. Ra., 112, 2552-2566, 2011.

Brown, A. T., Chipperfield, M. P., Richards, N. A. D., Boone, C., and Bernath, P. F.: Global stratospheric fluorine inventory for 2004-2009 from Atmospheric Chemistry Experiment Fourier Transform Spectrometer (ACE-FTS) measurements and SLIMCAT model simulations, Atmos. Chem. Phys., 14, 267-282, doi:10.5194/acp-14-267-2014, 2014.

Chipperfield, M. P.: Multiannual simulations with a threedimensional chemical transport model, J. Geophys. Res., 104, 1781-1805, doi:10.1029/98jd02597, 1999.

Chipperfield, M. P.: New version of the TOMCAT/SLIMCAT offline chemical transport model: Intercomparison of stratospheric tracer experiments, Q. J. Roy. Meteor. Soc., 132, 1179-1203, 2006.

Chipperfield, M. P., Liang, Q., Strahan, S. E., Morgenstern, O., Dhomse, S. S., Abraham, N. L., Archibald, A. T., Bekki, S., Braesicke, P., Di Genova, G., Fleming, E. L., Hardiman, S. C., Iachetti, D., Jackman, C. H., Kinnison, D. E., Marchand, M., Pitari, G., Pyle, J. A., Rozanov, E., Stenke, A., and Tummon, F.: Multimodel estimates of atmospheric lifetimes of long-lived ozonedepleting substances: Present and future, J. Geophys. Res.Atmos., 119, 2555-2573, doi:10.1002/2013JD021097, 2014.

Chipperfield, M. P., Dhomse, S. S., Feng, W., McKenzie, R. L., Velders, G., and Pyle, J. A.: Quantifying the ozone and UV benefits already achieved by the Montreal Protocol, Nat. Commun., 6, 7233, doi:10.1038/ncomms8233, 2015.

Connor, B. J. and Rodgers, C. D.: A comparison of retrieval methods: Optimal estimation, onion peeling, and a combination of the two, in: RSRM 1987: Advances in Remote Sensing Retrieval Methods, edited by: Deepak, A., Fleming, H. E., and Theon, J. S., A. Deepak Publishing, Hampton, Virginia, USA, 1989.

Dhomse, S., Chipperfield, M. P., Feng, W., Hossaini, R., Mann, G. W., and Santee, M. L.: Revisiting the hemispheric asymmetry in mid-latitude ozone changes following the Mount Pinatubo eruption: A 3-D model study, Geophys. Res. Lett., 42, 3038-3047, doi:10.1002/2015GL063052, 2015.

Duchatelet, P., Demoulin, P., Hase, F., Ruhnke, R., Feng, W., Chipperfield, M. P., Bernath, P. F., Boone, C. D., Walker, K. A., and Mahieu, E.: Hydrogen fluoride total and partial column time series above the Jungfraujoch from long-term FTIR 
measurements: Impact of the line-shape model, characterization of the error budget and seasonal cycle, and comparison with satellite and model data, J. Geophys. Res., 115, D22306, doi:10.1029/2010JD014677, 2010.

Feng, W., Chipperfield, M. P., Dorf, M., Pfeilsticker, K., and Ricaud, P.: Mid-latitude ozone changes: studies with a 3-D CTM forced by ERA-40 analyses, Atmos. Chem. Phys., 7, 2357-2369, doi:10.5194/acp-7-2357-2007, 2007.

Froidevaux, L., Anderson, J., Wang, H.-J., Fuller, R. A., Schwartz, M. J., Santee, M. L., Livesey, N. J., Pumphrey, H. C., Bernath, P. F., Russell III, J. M., and McCormick, M. P.: Global OZone Chemistry And Related trace gas Data records for the Stratosphere (GOZCARDS): methodology and sample results with a focus on $\mathrm{HCl}, \mathrm{H}_{2} \mathrm{O}$, and $\mathrm{O}_{3}$, Atmos. Chem. Phys., 15, 1047110507, doi:10.5194/acp-15-10471-2015, 2015.

Fu, D., Boone, C. D., Bernath, P. F., Weisenstein, D. K., Rinsland, C. P., Manney, G. L., and Walker, K. A.: First global observations of atmospheric COClF from the Atmospheric Chemistry Experiment mission, J. Quant. Spectrosc. Ra., 110, 974-985, 2009.

Harrison, J. J., Chipperfield, M. P., Dudhia, A., Cai, S., Dhomse, S., Boone, C. D., and Bernath, P. F.: Satellite observations of stratospheric carbonyl fluoride, Atmos. Chem. Phys., 14, 1191511933, doi:10.5194/acp-14-11915-2014, 2014.

Irion, F. W., Gunson, M. R., Toon, G. C., Chang, A. Y., Eldering, A., Mahieu, E., Manney, G. L., Michelsen, H. A., Moyer, E. J., Newchurch, M. J., Osterman, G. B., Rinsland, C. P., Salawitch, R. J., Sen, B., Yung, Y. L., and Zander, R.: Atmospheric Trace Molecule Spectroscopy (ATMOS) Experiment Version 3 data retrievals, Appl. Optics, 41, 6968-6979, 2002.

Kohlhepp, R., Ruhnke, R., Chipperfield, M. P., De Mazière, M., Notholt, J., Barthlott, S., Batchelor, R. L., Blatherwick, R. D., Blumenstock, Th., Coffey, M. T., Demoulin, P., Fast, H., Feng, W., Goldman, A., Griffith, D. W. T., Hamann, K., Hannigan, J. W., Hase, F., Jones, N. B., Kagawa, A., Kaiser, I., Kasai, Y., Kirner, O., Kouker, W., Lindenmaier, R., Mahieu, E., Mittermeier, R. L., Monge-Sanz, B., Morino, I., Murata, I., Nakajima, H., Palm, M., Paton-Walsh, C., Raffalski, U., Reddmann, Th., Rettinger, M., Rinsland, C. P., Rozanov, E., Schneider, M., Senten, C., Servais, C., Sinnhuber, B.-M., Smale, D., Strong, K., Sussmann, R., Taylor, J. R., Vanhaelewyn, G., Warneke, T., Whaley, C., Wiehle, M., and Wood, S. W.: Observed and simulated time evolution of $\mathrm{HCl}, \mathrm{ClONO}_{2}$, and $\mathrm{HF}$ total column abundances, Atmos. Chem. Phys., 12, 3527-3556, doi:10.5194/acp12-3527-2012, 2012.

Mahieu, E., Duchatelet, P., Demoulin, P., Walker, K. A., Dupuy, E., Froidevaux, L., Randall, C., Catoire, V., Strong, K., Boone, C. D., Bernath, P. F., Blavier, J.-F., Blumenstock, T., Coffey, M., De Mazière, M., Griffith, D., Hannigan, J., Hase, F., Jones, N., Jucks, K. W., Kagawa, A., Kasai, Y., Mebarki, Y., Mikuteit, S., Nassar, R., Notholt, J., Rinsland, C. P., Robert, C., Schrems, O., Senten, C., Smale, D., Taylor, J., Tétard, C., Toon, G. C., Warneke, T., Wood, S. W., Zander, R., and Servais, C.: Validation of ACEFTS v2.2 measurements of $\mathrm{HCl}, \mathrm{HF}, \mathrm{CCl}_{3} \mathrm{~F}$ and $\mathrm{CCl}_{2} \mathrm{~F}_{2}$ using space-, balloon- and ground-based instrument observations, Atmos. Chem. Phys., 8, 6199-6221, doi:10.5194/acp-8-6199-2008, 2008.

Mahieu, E., Chipperfield, M. P., Notholt, J., Reddmann, T., Anderson, J., Bernath, P. F., Blumenstock, T., Coffey, M. T., Dhomse, S. S., Feng, W., Franco, B., Froidevaux, L., Griffith, D. W. T.,
Hannigan, J. W., Hase, F., Hossaini, R., Jones, N. B., Morino, I., Murata, I., Nakajima, H., Palm, M., Paton-Walsh, C., Russell III, J. M., Schneider, M., Servais, C., Smale, D., and Walker, K. A: Recent Northern Hemisphere stratospheric $\mathrm{HCl}$ increase due to atmospheric circulation changes, Nature, 515, 104-107, doi:10.1038/nature13857, 2014.

Monge-Sanz, B. M., Chipperfield, M. P., Simmons, A. J., and Uppala, S. M.: Mean age of air and transport in a CTM: Comparison of different ECMWF analyses, Geophys. Res. Lett., 34, L04801, doi:10.1029/2006g1028515, 2007.

Perrin, A., Demaison, J., and Toon, G.: The $v_{1}, v_{2}$, and $v_{3}$ bands of carbonyl chlorofluoride $(\mathrm{COFCl})$ at $5.3,9.1$, and $13.1 \mu \mathrm{m}$ : position and intensity parameters and their use for atmospheric studies, J. Quant. Spectrosc. Ra., 112, 1266-1279, doi:10.1016/j.jqsrt.2011.01.003, 2011.

Ploeger, F., Riese, M., Haenel, F., Konopka, P., Müller, R., and Stiller, G.: Variability of stratospheric mean age of air and of the local effects of residual circulation and eddy mixing, J. Geophys. Res.-Atmos., 120, 716-733, doi:10.1002/2014JD022468, 2015.

Plumb, R. A. and Ko, M. K. W.: Interrelationships between mixing ratios of long-lived stratospheric constituents, J. Geophys. Res., 97, 10145-10156, 1992.

Ricaud, P. and Lefevre, F.: Fluorine in the atmosphere, in: Fluorine and the Environment: Atmospheric Chemistry, Emissions, \& Lithosphere, edited by: Tressaud, A., Elsevier, Oxford, UK, 2006.

Rothman, L. S., Gamache, R. R., Tipping, R. H., Rinsland, C. P., Smith, M. A. H., Benner D. C., Devi, V. M., Flaud, J.-M., CamyPeyret, C., Perrin, A., Goldman, A., Massie, S. T., Brown, L. R., and Toth, R. A.: The HITRAN molecular database: Editions of 1991 and 1992, J. Quant. Spectrosc. Ra., 48, 469-507, 1992.

Rothman, L. S., Jacquemart, D., Barbe, A., Benner, C. D., Birk, M., Brown, L. R., Carleer, M. R., Chackerian Jr., C., Chance, K., Coudert, L. H., Dana, V., Devi, V. M., Flaud, J.-M., Gamache, R. R., Goldman, A., Hartmann, J.-M., Jucks, J. W., Maki, A. G., Mandin, J.-Y., Massie, S. T., Orphal, J., Perrin, A., Rinsland, C. P., Smith, M., Tennyson, J., Tolchenov, R. N., Toth, R. A., Vander Auwera, J., Varanasi, P., and Wagner, G.: The HITRAN 2004 molecular spectroscopic database, J. Quant. Spectrosc. Ra., 96, 193-204, 2005.

Rothman, L. S., Gordon, I. E., Babikov, Y., Barbe, A., Benner, D. C., Bernath, P. F., Birk, M., Bizzocchi, L., Boudon, V., Brown, L. R., Campargue, A., Chance, K., Cohen, E. A., Coudert, L. H., Devi, V. M., Drouin, B. J., Fayt, A., Flaud, J.-M., Gamache, R. R., Harrison, J. J., Hartmann, J.-M., Hill, C., Hodges, J. T., Jacquemart, D., Jolly, A., Lamouroux, J., Le Roy, R. J., Li, G., Long, D. A., Lyulin, O. M., Mackie, C. J., Massie, S. T., Mikhailenko, S., Müller, H. S. P., Naumenko, O. V., Nikitin, A. V., Orphal, J., Perevalov, V., Perrin, A., Polovtseva, E. R., Richard, C., Smith, M. A. H., Starikova, E., Sung, K., Tashkun, S., Tennyson, J., Toon, G. C., Tyuterev, Vl. G., and Wagner, G.: The HITRAN2012 molecular spectroscopic database, J. Quant. Spectrosc. Ra., 130, 4-50, 2013.

Russell III, J. M., Gordley, L. L., Park, J. H., Drayson, S. R., Hesketh, W. D., Cicerone, R. J., Tuck, A. F., Frederick, J. E., Harries, J. E., and Crutzen, P. J.: The Halogen Occultation Experiment, J. Geophys. Res., 98, 10777-10797, doi:10.1029/93JD00799, 1993. 
Russell III, J. M., Deaver, L. E., Luo, M., Cicerone, R. J., Park, J. H., Gordley, L. L., Toon, G. C., Gunson, M. R., Traub, W. A., Johnson, D. G., Jucks, K. W., Zander, R., and Nolt, I. G.: Validation of hydrogen fluoride measurements made by the Halogen Occultation Experiment from the UARS platform, J. Geophys. Res., 101, 10163-10174, 1996.

Velazco, V. A., Toon, G. C., Blavier, J.-F. L., Kleinböhl, A., Manney, G. L., Daffer, W. H., Bernath, P. F., Walker, K. A., and Boone, C.: Validation of the Atmospheric Chemistry Experiment by noncoincident MkIV balloon profiles, J. Geophys. Res., 116, D06306, doi:10.1029/2010jd014928, 2011.
Zander, R., Roland, G., and Delbouille, L.: Confirming the presence of hydrofluoric acid in the upper stratosphere, Geophys Res. Lett., 4, 117-120, 1977.

Zander, R., Roland, G., Delbouille, L., Sauval, A., Farmer, C. B., and Norton, R. H.: Monitoring of the integrated column of hydrogen fluoride above the Jungfraujoch Station since 1977 - the HF/HCl column ratio, J. Atmos. Chem., 5, 385-394, 1987. 